\title{
Lab-on-PCB and Flow Driving: A Critical Review
}

\author{
Francisco Perdigones (D)
}

check for

updates

Citation: Perdigones, F. Lab-on-PCB and Flow Driving: A Critical Review. Micromachines 2021, 12, 175.

https://doi.org/10.3390/mi12020175

Received: 31 December 2020

Accepted: 5 February 2021

Published: 10 February 2021

Publisher's Note: MDPI stays neutral with regard to jurisdictional clai$\mathrm{ms}$ in published maps and institutional affiliations.

Copyright: $\odot 2021$ by the author. Licensee MDPI, Basel, Switzerland. This article is an open access article distributed under the terms and conditions of the Creative Commons Attribution (CC BY) license (https:// creativecommons.org/licenses/by/ $4.0 /)$.
Electronic Engineering Department, Higher Technical School of Engineering, University of Seville, 41092 Seville, Spain; fperdigones@us.es

\begin{abstract}
Lab-on-PCB devices have been developed for many biomedical and biochemical applications. However, much work has to be done towards commercial applications. Even so, the research on devices of this kind is rapidly increasing. The reason for this lies in the great potential of lab-on-PCB devices to provide marketable devices. This review describes the active flow driving methods for lab-on-PCB devices, while commenting on their main characteristics. Among others, the methods described are the typical external impulsion devices, that is, syringe or peristaltic pumps; pressurized microchambers for precise displacement of liquid samples; electrowetting on dielectrics; and electroosmotic and phase-change-based flow driving, to name a few. In general, there is not a perfect method because all of them have drawbacks. The main problems with regard to marketable devices are the complex fabrication processes, the integration of many materials, the sealing process, and the use of many facilities for the PCB-chips. The larger the numbers of integrated sensors and actuators in the PCB-chip, the more complex the fabrication. In addition, the flow driving-integrated devices increase that difficulty. Moreover, the biological applications are demanding. They require transparency, biocompatibility, and specific ambient conditions. All the problems have to be solved when trying to reach repetitiveness and reliability, for both the fabrication process and the working of the lab-on-PCB, including the flow driving system.
\end{abstract}

Keywords: lab-on-PCB; microfluidics; flow driving; actuators; biomedical applications

\section{Introduction}

Lab-on-PCB has been the subject of increasing research over the last few years [1,2]. These devices emerged as a promising evolution of lab-on-chip devices [3-5] and the PCB-MEMS technology [6]. They share important properties with lab-on-chip devices-for example, small fluid volume and rapid response time. Particularly, the core of these devices is the integration of sensors for measuring the results of a reaction, and for controlling the parameters of the samples; and the integration of actuators for conditioning the samples and for moving those samples through the microfluidic platform.

The need for micromixing, microheating, and sensing in different parts of the microfluidic platforms makes the control of liquids mandatory. For this reason, the flow driving and fluid manipulation into a network of microchannels is one of the most important issues for lab-on-chip devices (LoC) and platforms [3,7], and particularly for lab-on-PCB. In this respect, the first attempts of developing a fluid manipulation date to late last century with a gas chromatographic air analyzer, and a miniaturized electrophoresis system $[8,9]$. Many works about flow driving have been carried out since those years, providing a large number of methods for performing similar tasks. Several of these methods have been integrated in lab-on-PCB: among others, pressurized microchambers, peristaltic pumps, and electrowetting on dielectrics.

Although lab-on-chip and lab-on-PCB have characteristics in common, and lab-onPCB can be considered as a kind of lab-on-chip, they are different platforms. For example, unlike lab-on-chips, lab-on-PCBs are interesting due to the easy integration of microfluidics and electronics in the same platform, towards self-contained systems for microfluidic applications [10-12]. Apart from the integration, the interest in lab-on-PCB devices lies 
in the commercial availability of the PCB substrate with very reasonable dimensions at low cost $[13,14]$. Thanks to this characteristic, the lab-on-PCB devices can be disposable at low cost. This is important because the cleaning cost can be avoided. In fact, the cleaning implies an auxiliary and integrated microfluidic circuit or the use of the external facilities. The first option means an increase of the chip area, and thus a higher price. The cost of the second option is not worth worrying about because the devices are inexpensive. Moreover, the cleaning of small microchannels is very demanding, especially in biomedical applications. Therefore, the best choice to avoid cross-contamination from the biological and economical point of view is the use of freshly fabricated devices. As previously said, lab-on-PCB devices are a very interesting option due to their low cost. This is an important difference with respect to lab-on-chip devices, and makes the lab-on-PCB devices an attractive choice from the market point of view. However, these single-use devices imply environmental issues due to the metals of the PCBs. Fortunately, the electronics industry has been using PCBs for over 50 years and this issue is solved.

The main differentiating characteristics of lab-on-chip and lab-on-PCB are summarized in Table 1.

Table 1. Main differentiating characteristics of lab-on-chip and lab-on-PCB.

\begin{tabular}{ccc}
\hline Characteristic & Lab-on-Chip & Lab-on-PCB \\
\hline Materials for microfluidics & Silicon, glass, plastic & PCB, plastic \\
Substrate materials & Silicon, glass, plastic & PCB (rigid/flexible) \\
Maximum number of metal layers & 2 (except silicon) & 30 [15] \\
Fabrication of electronic tracks & Yes & Yes (low cost) \\
Commercially available substrate & Yes & Yes (low cost/integrated electronics) \\
Impact-resistant chips & Brittle (Silicon, glass) & Robust \\
Transparency & Yes & No \\
Highly integrated electronics & Yes (Silicon) & SMD and through hole \\
Discrete electronic components & SMD & Yes (low cost) \\
Sensors/actuators integration & Yes & Medium \\
Sensing performance & High & Yes (insulation layer) \\
Biocompatibility & Yes & The rest of the applications \\
Best application scenario & Optical and /or high sensitivity & Yes \\
Disposable at low cost & Yes (plastic) & Very high \\
Potential of commercialization & Low &
\end{tabular}

As can be seen, the lab-on-PCB devices could be entirely fabricated using printed circuit boards; however, the lack of transparency makes them not very useful for optical measurement systems. In order to solve this issue, the PCB has been integrated with transparent materials, for example, glass, SU-8, PDMS, or kapton. For instance, the first platform integrating electronics and microfluidics using printed circuit boards (PCB) was developed by Jobst et al. [16] at the Technical University of Vienna in 1997, for the fabrication of a microdevice monitoring different metabolites by a biosensor array fabricated using glass. Two years later, Pagel and coworkers at the University of Rostock laid out the basis of the PCB technology, and they used it for developing several PCB-based devices, also named PCBMEMS devices [17-19]. The first lab-on-PCB itself also included a transparent cover. It was reported by Stefan Gassmann et al. [20] in 2007; see Figure 1. 

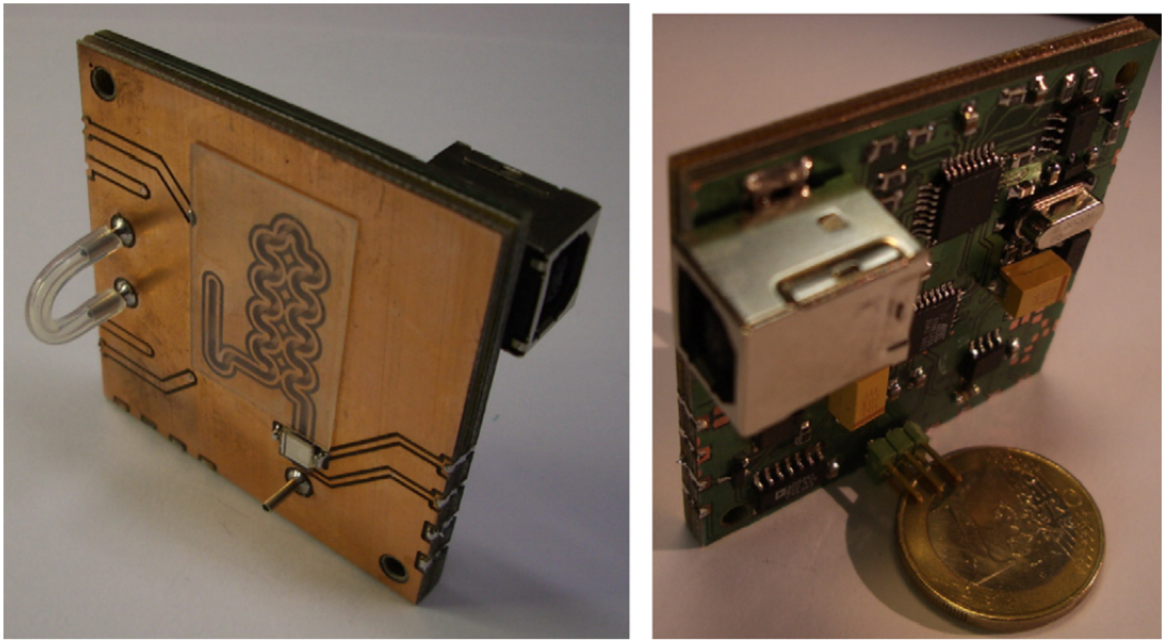

Figure 1. The first lab-on-PCB reported by Stefan Gassmann et al. (Reprinted from [20], copyright (2007), with permission from Elsevier).

This device was composed of a microfluidic platform with integrated electronics, sensors, actuators, a transparent cover, and fluid manipulation for the detection of $\mathrm{Fe}^{3+}$ that is, a lab-on-PCB with all its possible components and a specific application.

Glass, SU-8, PDMS, and kapton are very useful for fabricating prototypes, but there are better options with which to develop a commercial product. In this respect, an industrial labon-PCB device requires rapid mass production; that is, the fabrication of that product has to be performed at as low a cost as possible, while generating the largest number of products at the same time. For this reason, the thermoplastic materials are a good choice [21]. Most of them are transparent with a well-established mass production procedure, such as injection molding or hot embossing. These materials and fabrication methods should be chosen to fabricate a highly integrable flow driving systems, in order to develop marketable lab-on-PCB chips.

The final target in the development of lab-on-PCB devices lies on the mass production of commercial products. In fact, the fluid manipulation together with the PCB technology are very important from the point of view of the market, because they make it possible to tackle the development of inexpensive devices for many different biomedical and chemical analyses.

Nowadays, there is much work to do about the control of fluids and their integration into lab-on-PCB devices. Despite the improvements developed in recent years, lab-on-PCB is far from being robust. Unlike microelectronic chips, lab-on-PCB devices require a highly multidisciplinary R\&D group, and they have a lack of standardization for both design and end-user interfaces.

Regarding the future outlook, the authors suggest the reading of [1], especially the Section 4 , where a complete analysis of the future is performed.

Historically, the most used flow driving mechanisms in lab-on-chips, and especially in lab-on-PCBs are external pressure sources and syringe pumps. This is a well-established method, but reduces the portability of the whole system extremely. However, this method does not necessarily imply a disadvantage, as will be explained in the discussion section. The tendency to reduce or completely remove the connection between the microfluidic platform and the external sources is very positive from the portability point of view. Apart from the handling of fluids, the portability is hugely related to the marketable products. The reason for that lies in the commercial potential of the point of care devices, and the launch of new products into the market. The lab-on-PCB mechanisms mentioned in this review can seen in Figure 2. 


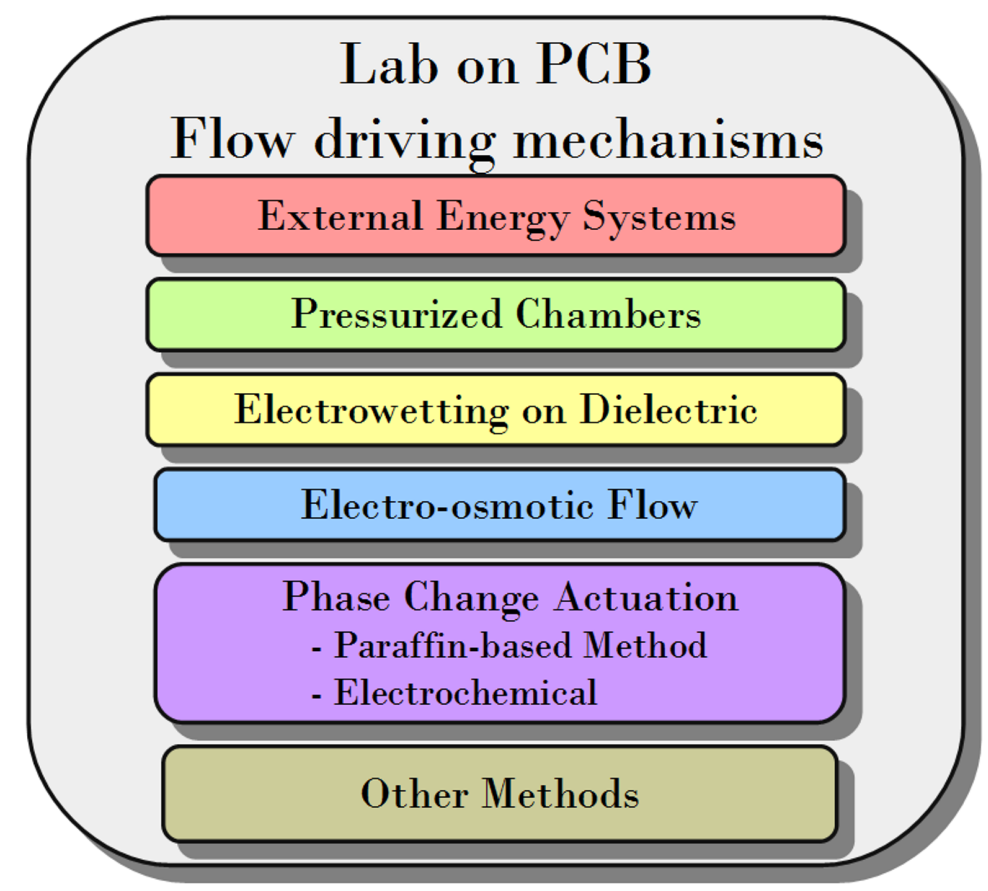

Figure 2. The external impulsion method together with the alternative ones mentioned in this review.

\section{External Energy Systems}

One of the most common methods to impulse liquids inside lab-on-chips and lab-onPCBs consists of using syringe pumps. This method implies the use of tubing to connect these energy sources with the microfluidic platforms. In general, the number of pressure sources is a function of the number of liquids. This could be excessive for large-scale integration in microfluidics [22,23]. For example, a prototype of a PCB-based biosensor for rapid detection of Salmonella in food products [24] is shown in Figure 3. As can be seen, five tubes are connected to the device.

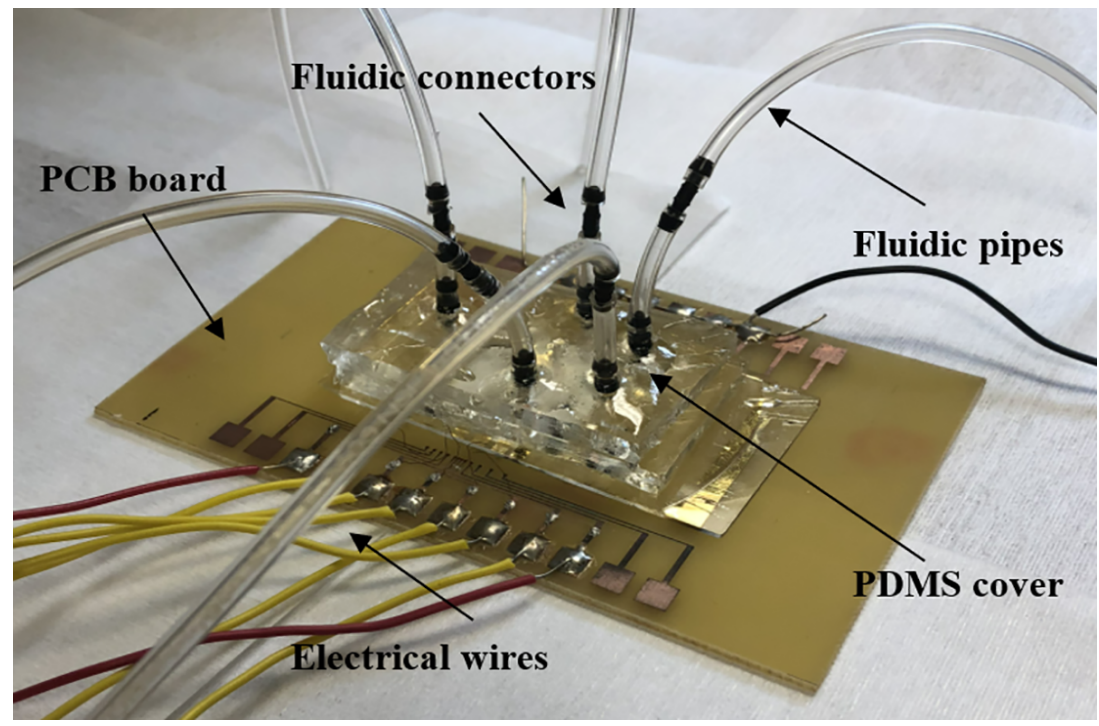

Figure 3. Prototype of a PCB-based biosensor for rapid detection of Salmonella in food products. The device requires the connection of five tubes, Ref. [24]. 
There are systems for multi-impulsion of liquids or gases to solve this problem, with the subsequent increase of cost. In addition, the connection of the tubes is an important issue to be solved. In this respect, multichannel chip-to-world interfaces for plug and play have been reported [25-27]. This solution consists of defining ports in microfluidics which tackle the required standardization. However, the portability continues to be an issue to face.

Many lab-on-PCB devices use external energy sources, such as syringe pumps, for moving the liquids with continuous flow. Although several combinations of external energy sources with lab-on-PCBs have been reported in the past [16,28-30], the examples chosen for this mechanism are a representative group of the recent past and present. For instance, the lab-on-PCB device reported by Moschou et al. [31] (2015) demonstrated the integration of stable $\mathrm{Ag} / \mathrm{AgCl}$ pseudo-reference electrodes. In order to do so, the authors used a laboratory syringe pump (Chemyx Inc., Fusion 200, Stafford, TX, USA) for moving a buffer continuously through the reference electrode over $24 \mathrm{~h}$. In 2017, a lab-on-PCB-based cytometer for detecting circulating tumor cells and enumeration was developed [32]. In this work, the biological samples were driven by a syringe pump (PHD 22/2000, Harvard Apparatus, MA, USA).

The PCB-based microfluidic platform for electrochemical detection of cancer biomarkers reported in [33] (2016) and the lab-on-PCB for conditioning the medium of cell cultures and mixing fluids described in [34] (2017), also require a connection to a syringe pump.

Recently, the PCB-based thermocycler for PCR developed in [35] (2019) required a syringe pump in order to move the DNA sample through a microchannel; the lab-on-PCB reported in [36] (2019) for organotypic cultures required continuous flow. Therefore, it needed to be connected to a external source (New Era Pump Systems, Inc, Farmingdale, NY, USA) to feed the tissues with culture medium. In addition, the lab-on-PCB for rapid and high sensitivity DNA quantification reported in [37] (2019) also made use of a syringe pump (Cole Palmer 230-CE) for continuous flow experiments; the reagents were delivered into the lab-on-PCB inlet; see Figure 4. The same syringe was used for delivering glucose samples in a lab-on-PCB for electrochemical glucose sensing (2020) [38]. Finally, peristaltic micropumps have also been used as external impulsion for lab-on-PCBs [39].

As can be seen, the external sources have been used for moving liquids in lab-on-PCBs from the beginning of this kind of device until today. This fact shows that this method continues being a good alternative to developing new devices with new applications. Although the external syringe pumps reduce the portability of the system, they are an interesting choice to demonstrate the integration of sensors and actuators in lab-on-PCB. Apart from this, many studies has been performed in order to remove the connection tubes from the microfluidic devices, aiming for portability. 


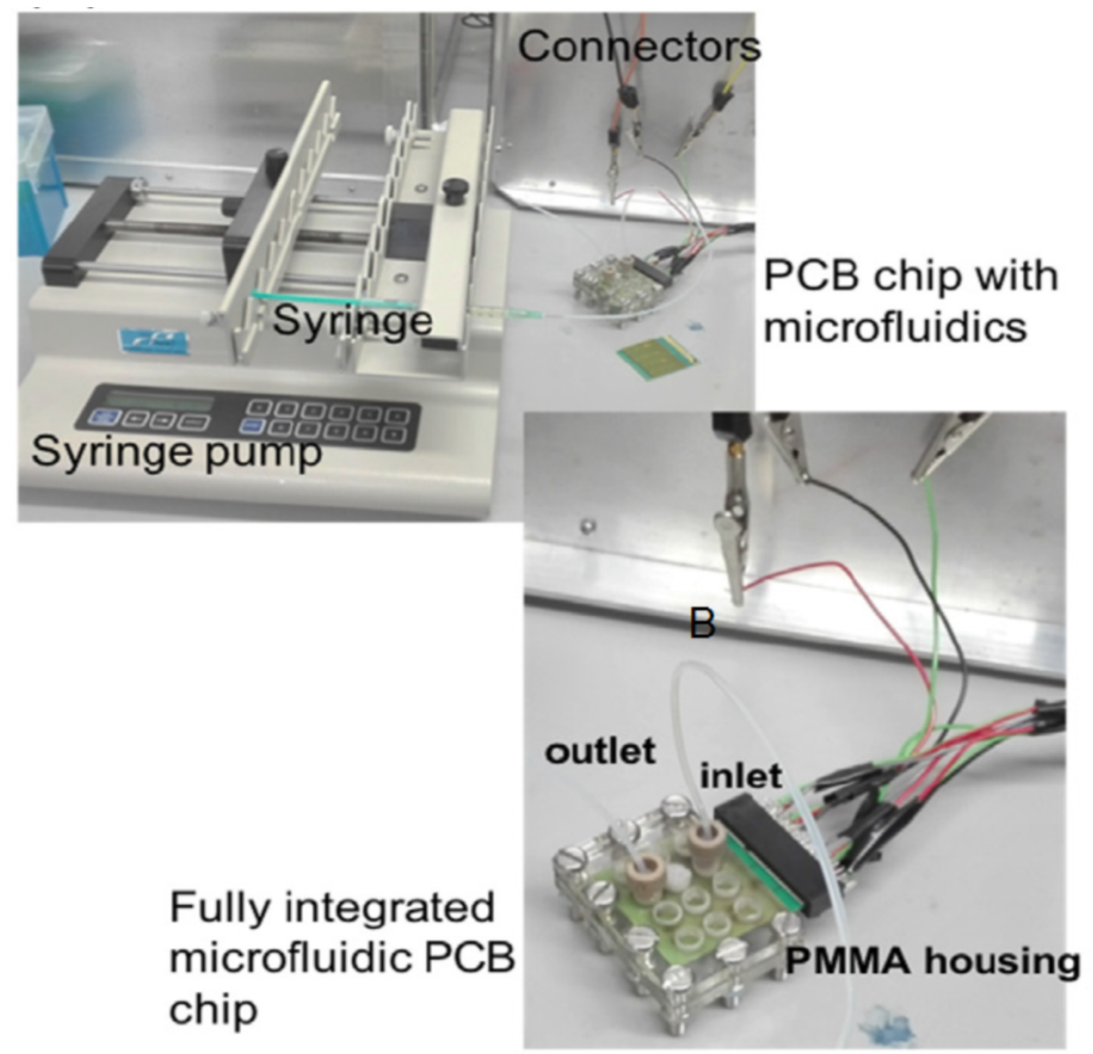

Figure 4. Lab-on-PCB for rapid and high sensitivity DNA quantification. The experiments are performed using an external syringe pump (Reprinted from [37], copyright (2019), with permission from Elsevier).

\section{Pressurized Chambers}

The method based on pressurized microchambers [40,41] is a good alternative for moving liquids in lab-on-PCBs. This is a mechanism which allows the storage of pneumatic energy in a microchamber of the lab-on-PCB, so that the connection tubes can be avoided. Once the energy is available, it can be released by the opening of a microvalve. The activation of those microvalves is electrically performed. In order to do so, a gold wire with a diameter of $25 \mu \mathrm{m}$ is used as a microheater.

The pneumatic energy is stored inside SU-8 microchambers as high pressure air. The releasing of the air is achieved by the destruction of a thin vertical wall due to both the increase of temperature and the pressure of the microchamber; see Figure 5A. The gold wire is perpendicular to the wall and so it is not optimal. In this respect, several microvalves with the wire completely embedded in the wall have been reported [42-44]. These devices have vertical walls except the ones described in [43,45], where the SU-8 wall was a membrane transferred to the PCB substrate; see Figure 5B. 

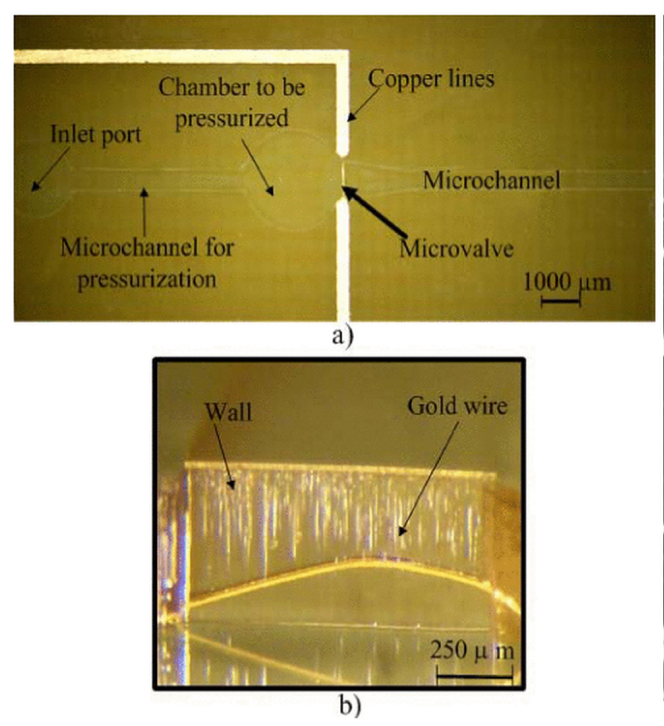

A

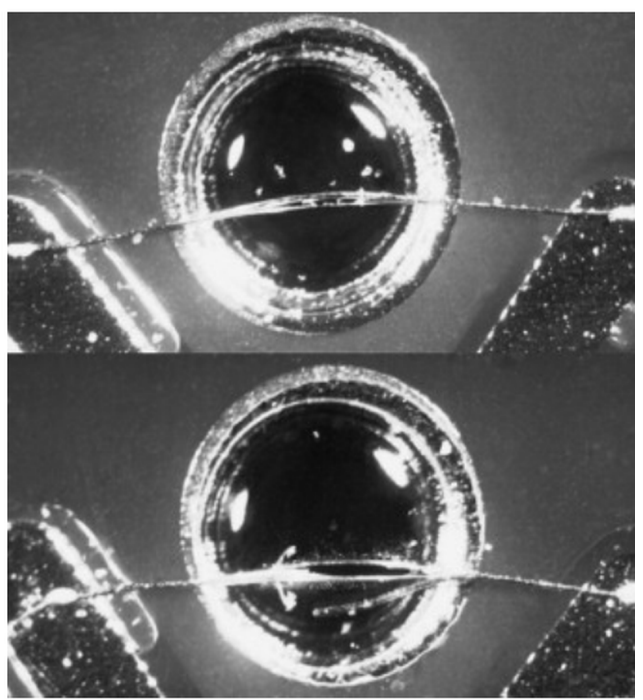

B

Figure 5. (A) Pressurized microchamber with vertical walls and an embedded gold wire (copyright (2014) IEEE. Reprinted, with permission, from [44]). (B) Pressurized microchamber composed of a planar SU-8 membrane with a completely embedded gold wire (Reprinted from [43], copyright (2010), with permission from Elsevier).

These microvalves were improved by using thin copper lines instead of wires $[40,46]$. They were fabricated by wet etching at the same time as the copper electronics tracks. This improvement implies the removing of the wire bonding step, so that the gold and the facilities involved to perform the bonding are avoided. In this case, the microvalve is used as a fuse, in order to destroy the SU- 8 wall. An example of these devices is shown in Figure 6.

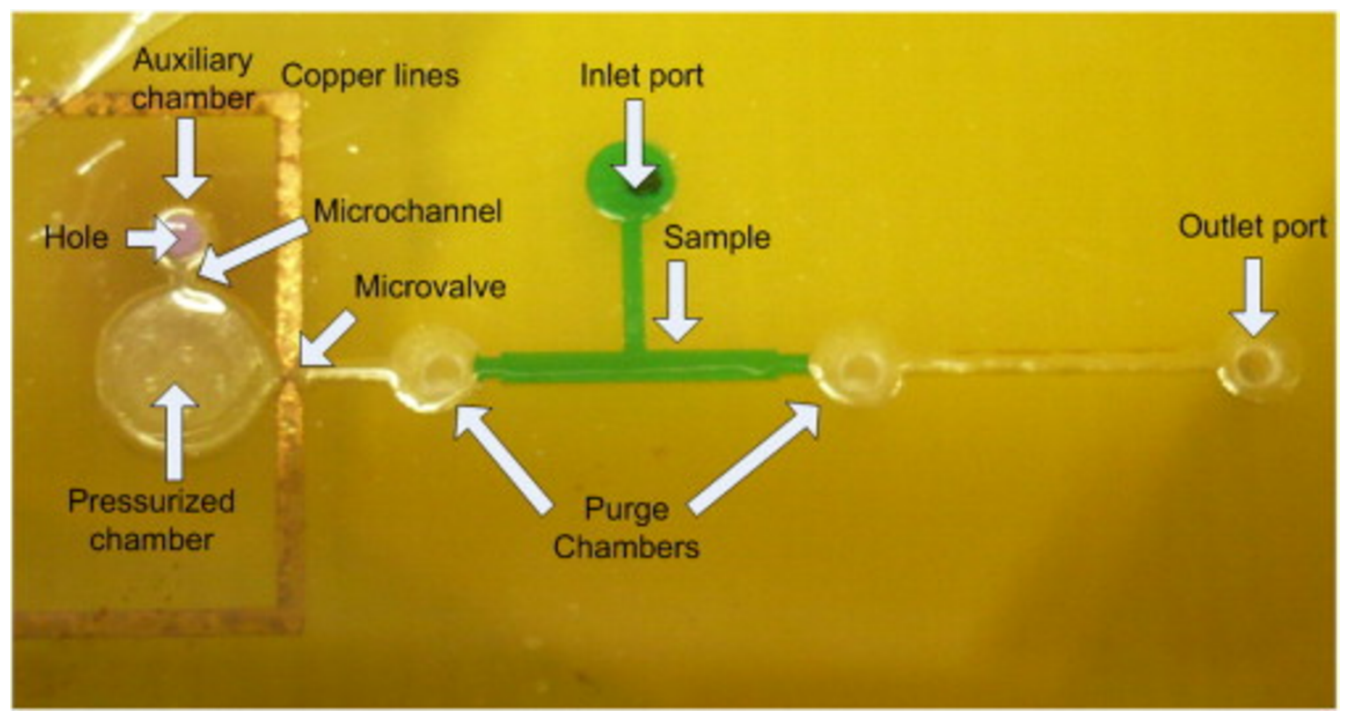

Figure 6. Impulsion system based on an SU-8 pressurized chamber and a copper line fuse. (Reprinted from [40], copyright (2015), with permission from Elsevier).

Several lab-on-PCB devices have been fabricated using this method-for example, the lab-on-PCB micromixer reported in [47], and the prototype developed to demonstrate the integration of a protocol in a lab-on-PCB platform [48].

Lab-on-PCBs have been fabricated using a thermoplastic (PMMA) and PCB, that is, materials compatible with mass production and multiple processes; see Figure 7 . This 
device is closer to a marketable product than those using SU-8-based materials. Actually, the device shown in Figure 7 is fabricated via a computer numerical control (CNC) machine. This is not a mass production procedure, but the PMMA can be processed by injection molding or hot embossing.

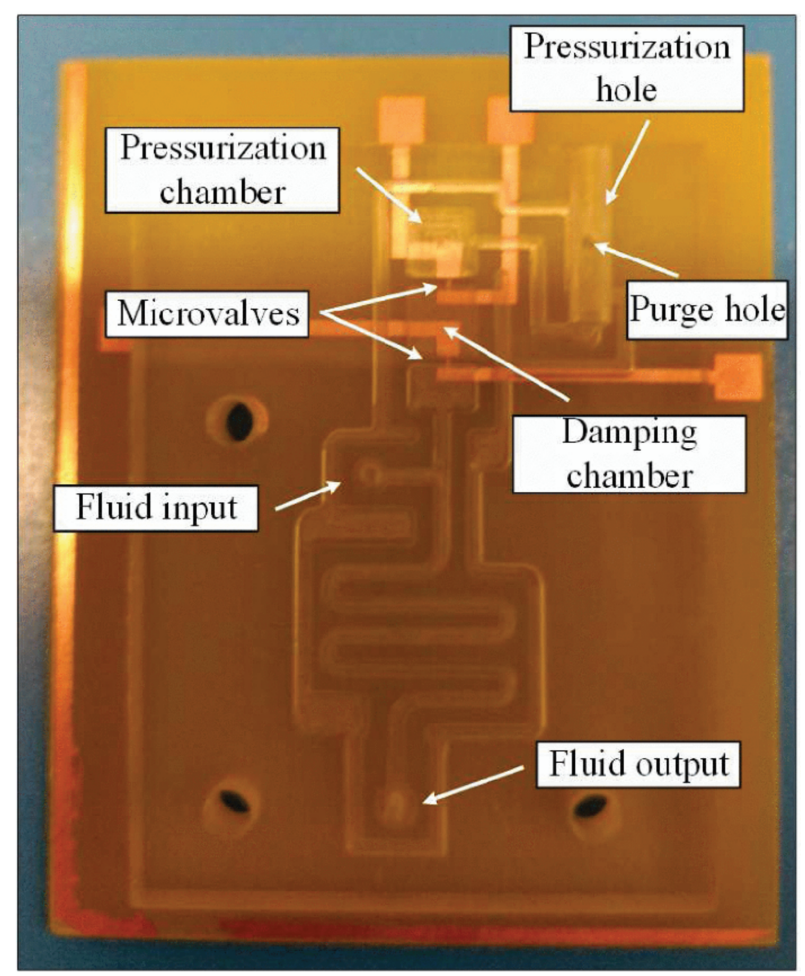

Figure 7. Pressurized chamber fabricated using a thermoplastic and PCB, with copper lines as a fuse [49]. (Copyright (2018) IEEE. Reprinted, with permission, from [49]).

In this case, the air has to be inserted in the microchamber using plungers [49]. The destruction of the fuse opens a small microchannel through which the air leaves the microchamber to impulse the liquid stored in the microfluidic circuit.

This method is mechanically simple due to the impulsion being based on no moving parts. With the electric energy required to destroy the copper fuse, the control and signal processing can be included in a unique electronic circuit.

Regarding the limitations of the method, it is important to comment on the lack of biocompatibility due to the destruction of the copper fuse. The debris of the copper lines could damage the biological samples. The authors propose an inert and intermediate liquid between the pressurized microchamber and the rest of the microfluidic circuit, so that the samples will never be in contact with the contaminated air. Nevertheless, the integration of the inert liquid reduces the simplicity of the whole system. In addition, it increases the complexity of fabrication. These facts imply an increase of the fabrication cost as a commercial product.

Finally, the gas permeability of the polymeric wall is important because the pressurized microchamber could discharge in the long-term. This is a problem for long-term storage as a product. Moreover, the handling of fluids using this method is limited to small samples. Continuous flow is not possible to achieve; for instance, the insertion of medium in a long-term cell culture cannot be managed by pressurized chambers. This is not a problem because this method is not intended to do so. There are better choices to those applications, for example, external energy sources. 


\section{Electrowetting on Dielectric}

Electrowetting on dielectrics (EWOD) is one of the typical techniques of digital microfluidics [50-52]. This is a method whereby an electric field changes the wetting of a droplet, in contact with insulated and hydrophobic electrodes. The droplets are placed between two parallel layers; the bottom one is the substrate, which includes an electrode array covered with thin dielectric layer, and the top layer could be either a passive top plate or a ground plate. This method consists of switching the voltage to electrodes, so that the surface tension gradient can be modified, generating asymmetric contact angles, and the subsequent driving forces. Thus, the droplet is moved in two dimensions.

Among others, the advantages of EWOD devices include flexible device geometry, compatibility with other technologies, and simple electronic instrumentation. In addition, this technique allows easy manipulation of several reagents at a time, with a reduction of reagent volume, a short analysis time, and high sensitivity. Despite these advantages, the biomolecular adsorption of biological material due to the hydrophobic layer, together with electrolysis and evaporation of the small volume of liquids, and cross-contamination are the drawbacks of the technique, to name a few.

The PCB technology provides several advantages to EWOD devices. The typical fabrication process of these devices implies expensive clean rooms when processing glass substrates, resulting in smooth surfaces with reliable motion of droplets at voltages below $100 \mathrm{~V}$. Integrated circuits offer the smooth surface topography required in the droplet manipulation. However, the PCB substrates provide low cost fabrication and quick turnaround time with slightly higher driven voltages [53].

Many studies have taken advantage of the up-sides. For instance, the platform reported in [54] demonstrates the combination of lab-on-PCB and EWOD for two-plate and one-plane devices. The two-plate fabricated devices were used for moving, dispensing, merging, and splitting droplets in the range of 150-300 nL. On the other hand, the one-plate devices managed droplets with volumes of up to $3 \mu \mathrm{L}$. In addition, Parylene-C and PDMS were used as dielectric layers and the voltages ranged between 300 and $500 \mathrm{~V}$ at $18 \mathrm{kHz}$. Similar platforms have been reported for biological application and lower driven voltages, about AC voltage of $200 \mathrm{~V}$ at $1 \mathrm{kHz}$, for moving droplets of about $30 \mu \mathrm{L}$ [55]. Besides, the works reported in [56] moved droplets of about $10 \mu \mathrm{L}$ with a speed of $3 \mathrm{~mm} / \mathrm{s}$ by applying a high DC voltage, $400 \mathrm{~V}$. This very low cost device is composed of a planar array of six electrodes with silicone rubber as the dielectric layer and a commercially available water repellent as the hydrophobic layer. A similar open platform was reported in [57]; a planar array of 64 electrodes was developed. In this work, silicone oil and Parafilm M were used as a dielectric hydrophobic layer. The speed was $15 \mathrm{~mm} / \mathrm{s}$ for droplets with a volume of $1850 \mu \mathrm{L}$, using a voltage output frequency of $10 \mathrm{~Hz}$. This device is shown in Figure 8, where the open EWOD platform and the electronic circuit to control the droplets can be seen. Unlike the previously mentioned devices, the one reported in [58] was a two plate system with an array of $24 \times 24$ electrodes controlled by seven control signals at 15-30 V. It was composed of a dielectric layer (SU-8) and a hydrophobic layer (Teflon AF1600) deposited on the PCB. 


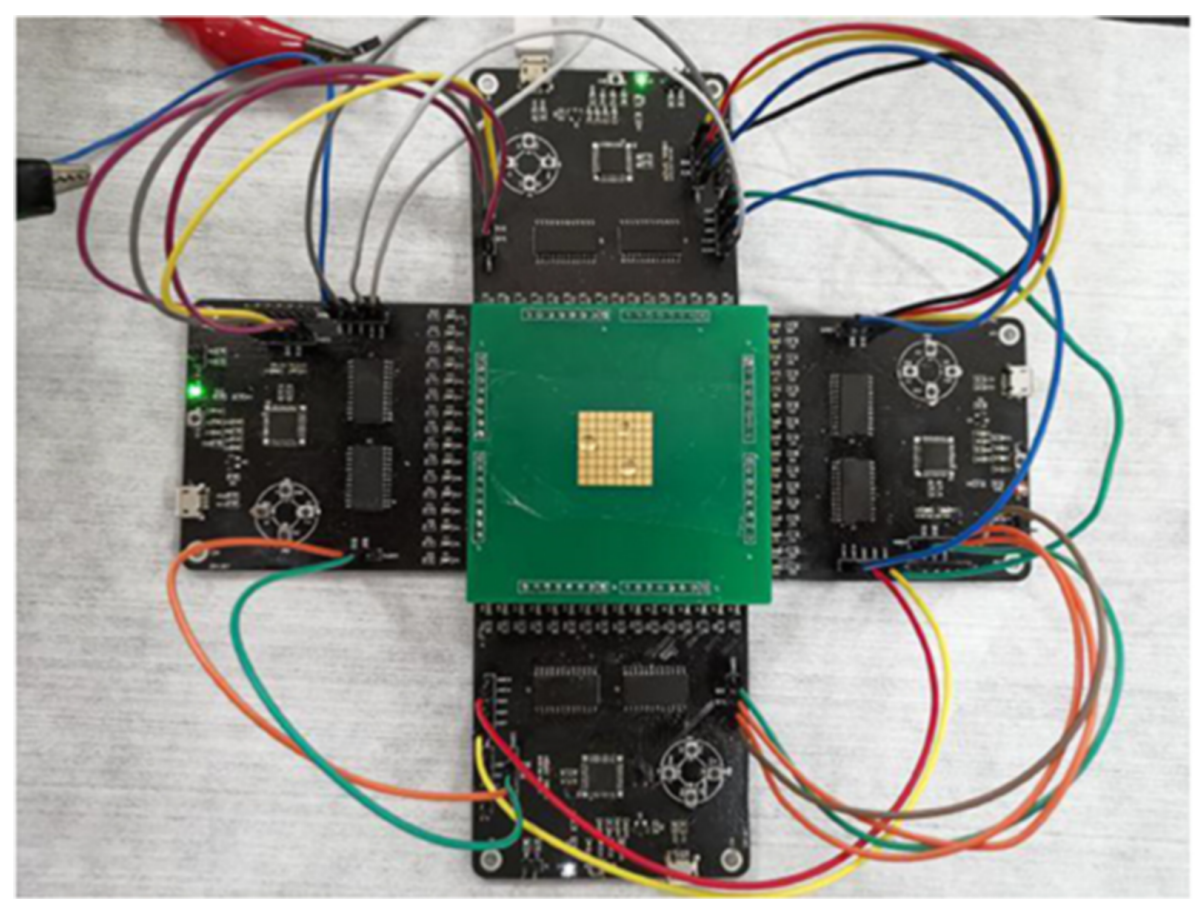

Figure 8. The open EWOD platform and the electronic circuit to control the droplets can be seen [57].

The work described in [53] scales the PCB-based electrowetting devices to larger arrays, with smooth surface topography if taking into account the roughness of the PCB substrate. The authors state that they successfully moved, merged, and mixed droplet with volumes from 2 to $1200 \mu \mathrm{L}$. On the other hand, multilayer PCB substrates have also been used for EWOD [59-61]. Finally, PCB has also been used for contactless electrowetting, that is, modifying the contact angle by air ionization [62].

Apart from these prototypes and studies, the development towards a commercial product reported in $[63,64]$ proposes droplet-based pyrosequencing and point of care devices as lab-on-PCB; see Figure 9.

In particular, the device is intended to perform both immunoassays for cardiac troponin I and real-time PCR assays with $300 \mathrm{~nL}$ droplets. Besides, the fabrication process is performed by utilizing mass production techniques.

As can be seen, lab-on-PCB devices based on electrowetting on dielectrics are a very interesting choice for many biological applications [65]. The technology is mature enough to stimulate the creation of companies based on PCB for biomedical applications [66].

In general, the problem with this kind of platform is related with the number of electrodes and the electronic circuit; that is, a large number of electrodes implies a larger number of electronic components in the circuit. Even so, this fact does not seem to be a drawback for industrial production. Regarding the fabrication process, it only requires the commercially available printed circuit board process and several coatings, together with a plastic part to store liquids. Finally, it is worth mentioning that this method does not necessarily require microchannels, and thus the related fabrication processes. 

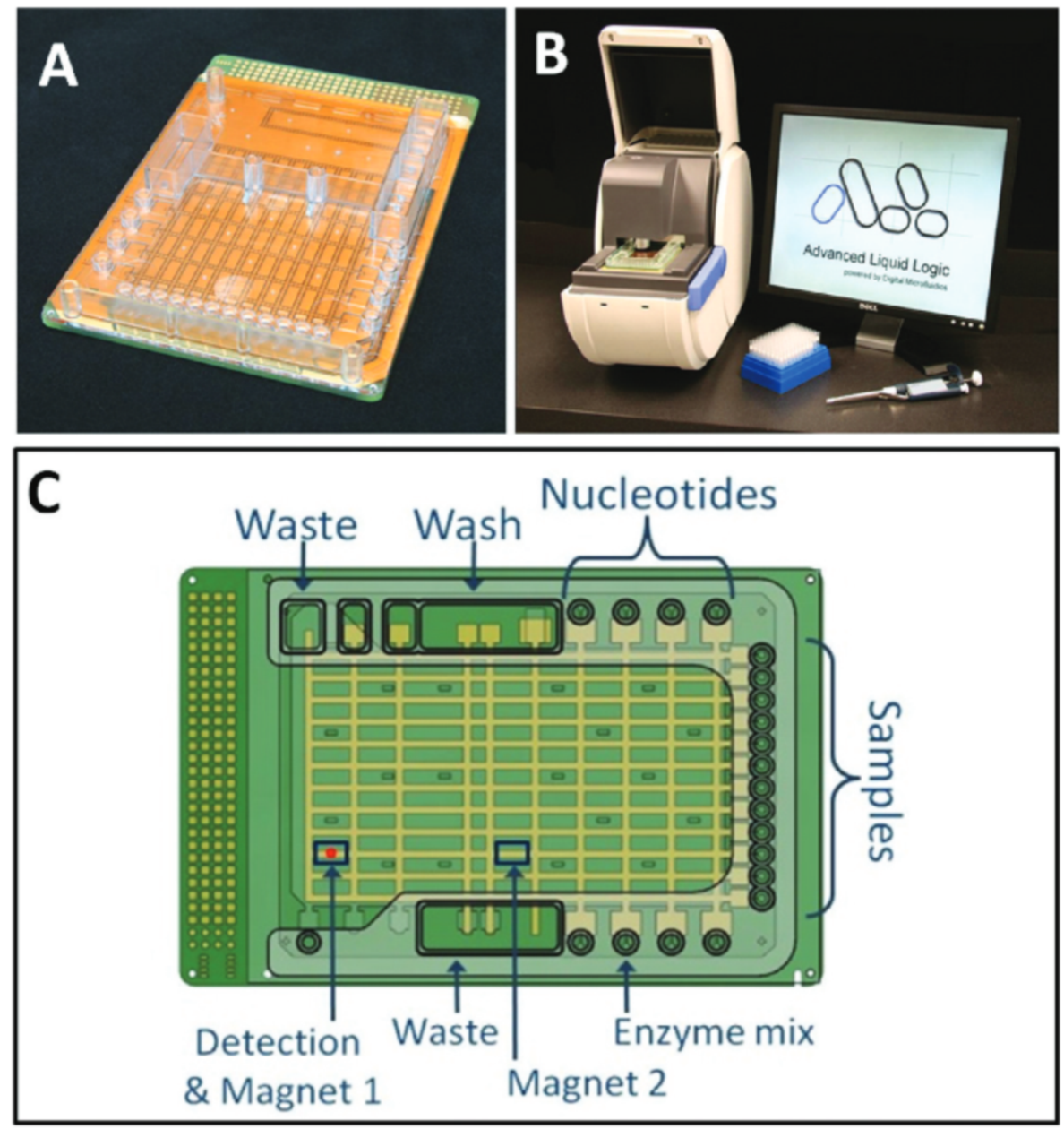

Figure 9. (A) Assembled multiwell-plate-sized PCB-based cartridge. (B) Photograph of the control instrument. and (C) Sketch of the cartridge showing the locations of sample and reagent wells (Reprinted with permission from [63], copyright (2011), American Chemical Society).

\section{Electroosmotic Flow}

This kind of pump is based on an electrokinetic phenomenon (electroosmosis) $[52,67,68]$. This process is used for impulsion liquids through microchannels or porous media, via the application of an external electric field. The electroosmotic effect takes place when fluids containing polar molecules are in contact with solid surfaces, so that electric charges appear in those surfaces which are in contact with the liquids. Those charges are negative when the working fluid is water in contact with an insulating solid. In addition, positive charges are induced at the same time in a thin layer of the water very close to the surface, in order to keep the electric neutrality. The layers of electrical charges of the fluid are named "Helmholtz layers", and the combination of these positive and negative layers is called the "electrical double layer". When an electrical field is applied inside the microchannel, forces appear on the positive layer and the charges are moved towards the negative electrode, transporting the liquid with them. The majority of electroosmotic pumps worked under direct current voltage. However, bubbles could appear at the driven electrodes due to the electrolysis. In this respect, the use of low alternating voltage can reduce or even eliminate the generation of bubbles

Among other things, the main advantage of electroosmotic pumps is the generation pulse-free flows. In addition, the flow magnitude and direction can change instantly. Finally, like the impulsion systems based on pressurized chambers, electroosmotic pumps have no moving parts. Regarding the limitations, electrolysis and the bubble generation could appear at the metal electrodes. Moreover, the flow rates are low if compared to other 
integrated micropumps, and the microchannels required to achieved a given flow rate are relatively narrow.

Printed circuit boards are a good candidate to develop electroosmotic pumps due to their metal layer. This layer is used for fabricating the driven electrodes with the typical photolithographic process. Consequently, the integration can be performed with ease. The rest of the electroosmotic pump has to be fabricated with a different material.

Several electroosmotic pumps have been integrated on PCBs-for example, the prototype reported in [69], which was fabricated using a PCB and SU-8; the Flame Retardant 4 (FR4) was the substrate, SU-8 was the material chosen with which to fabricate the microchannels and microchambers, and the copper layer was used for building the electrodes, electrical connections, and pads. The device is inexpensive but the materials make the mass production difficult. A similar pump with the same fabrication process was reported in [70]; see Figure 10. This pump is able to provide a flow rate of $1 \mu \mathrm{L} / \mathrm{min}$ at a direct current voltage of $60 \mathrm{~V}$.

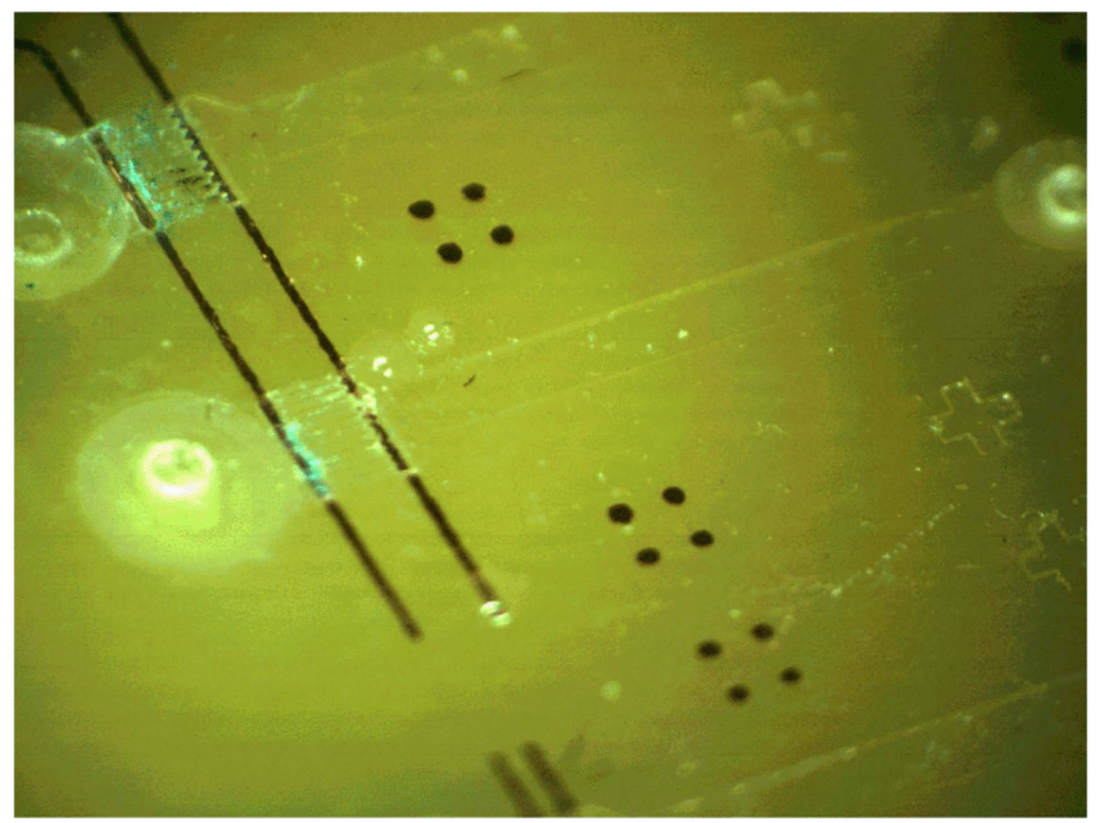

Figure 10. Prototype of an electroosmotic micropump for lab-on-PCBs. (Copyright (2012) IEEE. Reprinted, with permission, from [70]).

A different material was integrated with the PCB in a study presented in [71]; the authors describe a lab-on-PCB compatible with this flow driving method. The fabrication materials include a dry resist and $\mathrm{PCB}$, and require hot pressing and several photolitographic processes. In addition, it includes surface mounted electronic components (SMD) intended to take measurements; for example, the authors performed optical experiments via the integration of two embedded SMD blue LEDs. They also integrated a temperature sensor and a resistor.

The work reported in [72] shows the design and characterization of a passive, disposable wireless for lab-on-PCB for particle and fluid manipulation. Unlike the previously mentioned devices, this one was fabricated on a flexible PCB (lab-on-a-film) integrating a receiving coil, an array of interdigitated electrodes (IDE), and two SMD components, a diode and a capacitor. It works at low voltages, and can perform three microfluidic operations depending on the wirelessly-controlled voltage, so that when the signal over an array of interdigitated electrodes is about $0.7 \mathrm{~V}$, the IDE performs particle enrichment. The IDE works as an active mixer at $2 \mathrm{~V}$; and as an AC electroosmotic pump when the voltage is $3 \mathrm{~V}$. All of these functions are performed by the device itself with overall dimensions of $10 \times 20 \mathrm{~mm}^{2}$; see Figure 11 . 


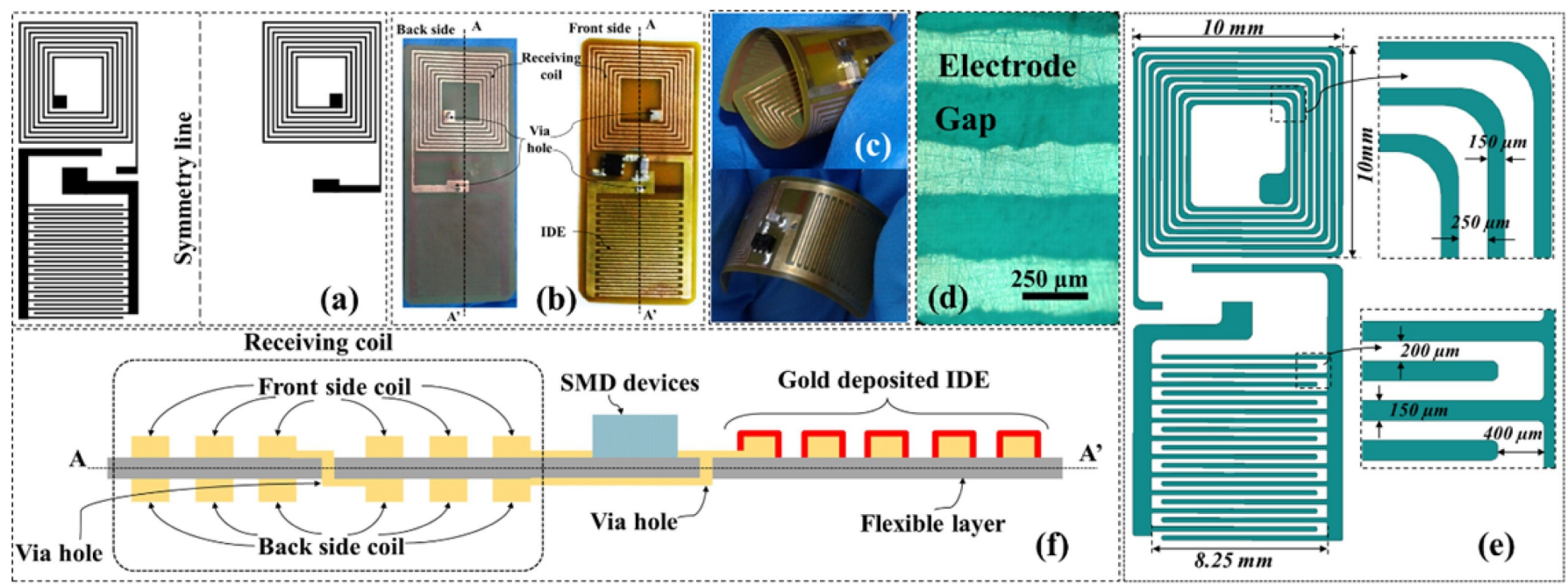

Figure 11. (a) Layout used for the device fabrication, (b) fabricated biased-AC electroosmotic lab-on-a-film pad, (c) demonstration of the device's flexibility, (d) detail of the metal traces, (e) dimensions of the device pad, (f) cross-sectional view of the device along AA' cut (Reprinted from [72], copyright (2016), with permission from Elsevier).

Finally, the micropump reported in [73] can be surface mounted on a commercial PCB. This pump is composed of a nanoporous membrane to provide an electroosmotic flow for a maximum flow rate of $8 \mu \mathrm{L} / \mathrm{s}$ at a voltage of $2 \mathrm{~V}$.

Summarizing, electroosmotic pumps have been integrated into lab-on-PCBs for fluid manipulation. They provide a low cost choice for electrically controlled pulse-free continuous flows compatible with the integration of sensor and actuators. Nevertheless, external or integrated liquid reservoirs and narrow microchannels are required. In addition, electrolysis and bubbles could appear with inappropriate activation. On the other hand, the working of these devices with copper electrodes implies oxidation and the subsequent contamination of the fluid, and eventually the blocking of the microchannels (see the electrodes of the device of Figure 10). In order to avoid the oxidation, additional fabrication steps are required so that the fabrication cost increases due to both new facilities and new fabrication materials. In addition, the narrow microchannels are difficult to fabricate with mass production equipment with reasonable tolerance at low cost. This means a drawback from the industrial point of view.

\section{Phase Change Actuation}

The flow driving systems based on phase changes, such as microvalves and micropumps, have been used for microfluidic handling. The main methods for this purpose are based on paraffin [74] and electrochemical micropumps.

The paraffin-based method makes use of the thermal properties of the paraffin to change its phase from solid to liquid and vice versa. This material modifies its volume as a function of the temperature so that the higher the temperature is, the more the paraffin increases its volume, typically about $10-15 \%$. This increase of volume and the melting are used for opening and closing valves in order to modify a flow rate. These systems have been included in lab-on-PCB platforms due to their advantages, such as simple design, and more importantly, the low cost of the paraffin. In addition, the paraffin-based valves can be activated several times, and they support high pressures [75]. However, these devices have several drawbacks, for example, the integration of the paraffin. Moreover, the characteristic of the material makes the complete system temperature-dependent. Finally, the time response to manipulate the liquids is high, about tens of seconds.

The increase of temperature required to change the phase of the paraffin has to be performed using a thermal actuator, that is, a microheater. Thus, the copper layer of the PCB substrate is very suitable to fabricate that microheater. It is developed as a serpentine 
copper line whose heating is governed by the Joule effect. This fact makes the paraffinbased actuation method easy to integrate in lab-on-PCB.

The paraffin-based method for fluid manipulation has been integrated in several lab-on-PCBs. Bodén et al. [76], in 2008, developed an on-chip liquid storage and dispensing for lab-on-PCB. The system has three integrated liquid reservoirs and dispenser units for $10 \mu \mathrm{L}$ sample volumes. Those reservoirs can store either reagents or liquids for buffering or rinsing. The device is composed of a PCB substrate with an integrated copper microheater and an epoxy structure for the microfluidic circuit. Once the microheater is activated, the paraffin melts and expands, increasing the pressure. Therefore, the fluid is driven toward the microchambers and microchannels.

Recently, in 2019, Wang et al. [77] reported an on-board control of paraffin-based microfluidics manipulation on an active centrifugal lab-on-PCB for plasmid DNA extraction. The impulsion is based on both centrifugal forces and heating. The device is composed of a plastic microfluidic layer fabricated using a PMMA master, and a commercial PCB layer as a substrate. The heating is achieved by resistors in a PCB substrate. Unlike the previously mentioned paraffin-based lab-on-PCBs, the resistors are not serpentine-shaped copper lines. In this case, the temperature is raised using SMD resistors as thermal actuators. This implies a lower area of heating compared with the copper lines. Once the paraffin is melted, the centrifugal forces drive the fluid.

Regarding the electrochemical method, the most representative one is based on electrolysis, that is, the gas generation inside a liquid. Typically, the chosen liquid is water because it is inexpensive and easy to work with, and the resulting gases are hydrogen and oxygen. This method was applied to a PCB-based micropump with the maximum flow rate of $31.6 \mathrm{~mL} / \mathrm{min}$ and maximum backpressure of $547 \mathrm{kPa}$ (at $34 \mu \mathrm{L} / \mathrm{min})$ [78,79]. The water electrolysis is achieved using integrated interdigitated microelectrodes on the $\mathrm{PCB}$, where the metal of the electrodes is fabricated using the copper layer of the PCB with electroplated gold; see Figure 12.

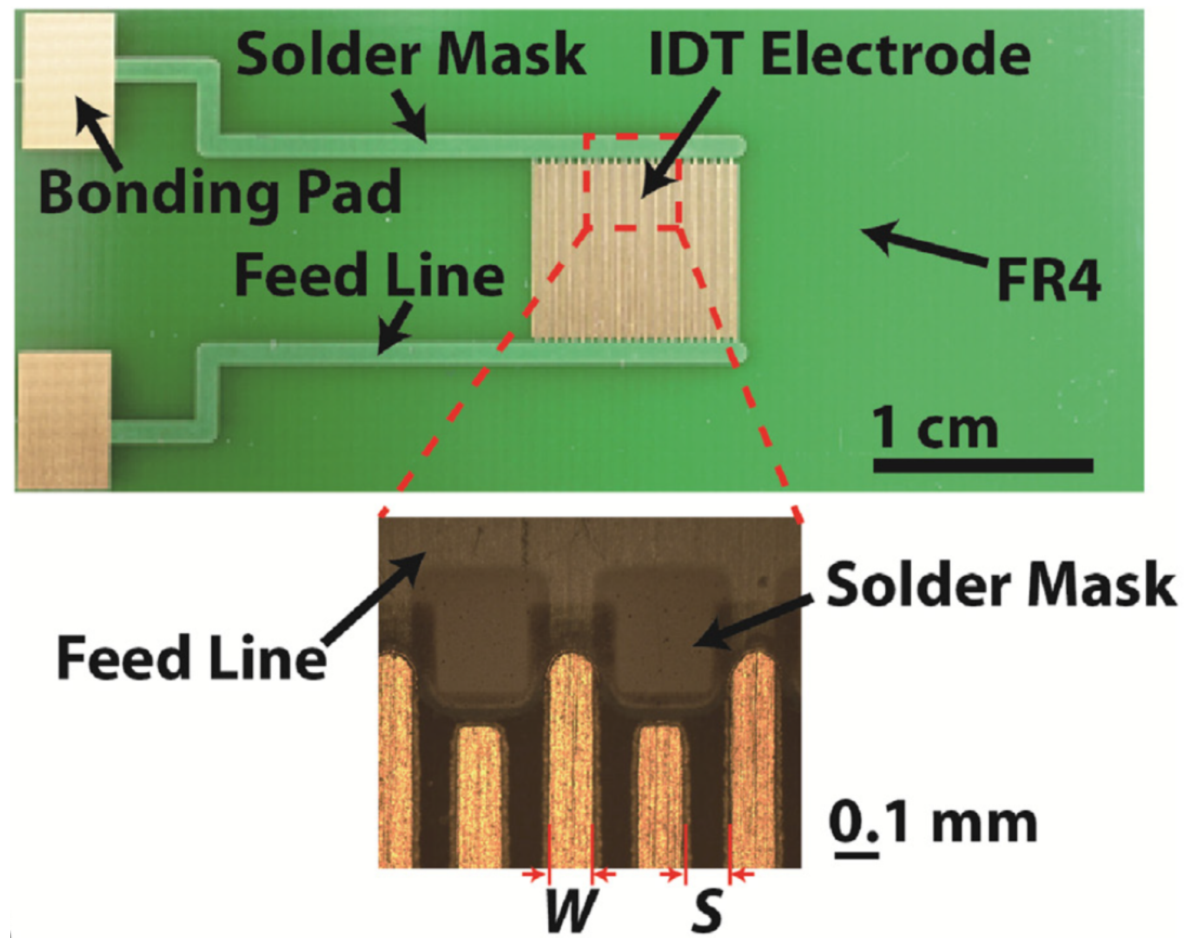

Figure 12. Electrochemical PCB-based impulsion chip with enlarged detail of the microelectrode fingers (Reprinted from [78], copyright (2018), with permission from Elsevier).

A similar method was reported in [80] with a flow rate ranging from $20 \mu \mathrm{L} / \mathrm{min}$ to $135 \mu \mathrm{L} / \mathrm{min}$. This device also uses integrated metal electrodes to perform the electrolysis 
of water. However, the electrodes are made of copper without electroplated gold. The very well-finished lab-on-PCB reported in [81] also uses the electrolytic gas generation inside a hydrogel. These electrolytic and PCB-based impulsion systems require the precise integration of a material inside the system, especially the last one, where the hydrogel has to be dispensed into the microchambers. Finally, the electrolytic method was applied for flow driving in a USB-based lab-on-PCB device for microparticle generation [82].

Finally, the self-contained, fully integrated lab-on-PCB for sample preparation, PCR amplification, and DNA detection [11] is one of the most representative lab-on-PCB which uses, among other things, electrochemical flow driving. The device includes microchannels, microchambers, micromixers, microvalves, micropumps, and microheaters. The chip is able to manipulate initial samples in the order of microliters and milliliters. In order to do so, electrochemical micropumps are used for driving milliliter volumes. It is based on the electrolysis of water between two platinum electrodes to generate gases when a current is applied. These gases increase the pressure that moves liquids in the device. In addition, a thermopneumatic pump for driving microliter volumes is used. The expansion of the gas is performed in a chamber attached to a PCB-based and resistive microheater. The resulting air expansion drives the liquids into the microchannels and microchambers of the device. Moreover, this device also integrates paraffin-based microvalves for fluid manipulation in lab-on-PCB; see Figure 13. The same authors from Motorola Labs used these actuators for DNA amplification, Ref. [83]. The device was composed of a PCR chamber and paraffinbased microvalves. Escherichia coli K12 cells were used in the experiments. Regarding the main fabrication materials, the device was built using mass production materials, that is, polycarbonate and a PCB as the substrate. The fluid manipulation was performed by resistive microheaters to provide the thermal actuation to the paraffin.

Summarizing, the mentioned paraffin-based lab-on-PCBs are robust platforms for microfluidic handling. The reported results are promising, as can be deducted from the reported biomedical applications. Nevertheless, the integration of the paraffin implies complex fabrication steps which go against the low cost mass production, and the subsequent competitiveness as a commercial product. The electrochemical methods are also robust but they have the same drawback as the paraffin-based one, that is, the integration of a small quantities of materials-in this case, water or hydrogels.

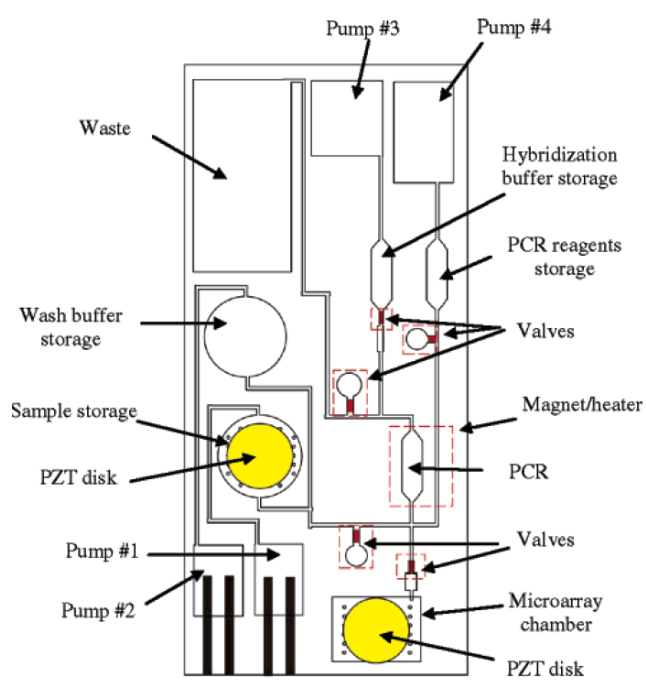

A

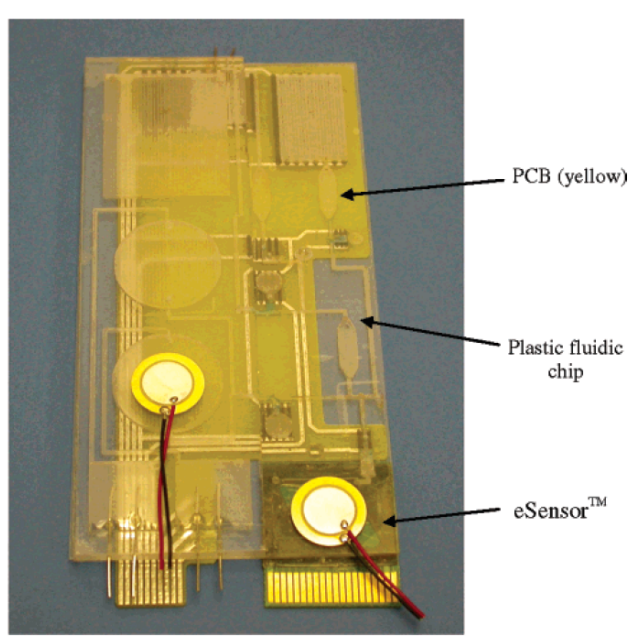

B

Figure 13. Self-contained, fully integrated lab-on-PCB for sample preparation, PCR amplification, and DNA detection. (A) Sketch of the plastic fluidic lab-on-PCB. Micropumps 1-3 are electrochemical, and pump 4 is thermopneumatic. (B) The integrated lab-on-PCB consists of a plastic microfluidic chip, a printed circuit board (PCB) substrate, and a Motorola eSensor microarray chip (Reprinted with permission from [11], copyright (2004), American Chemical Society). 


\section{Other Methods}

Apart from the previously mentioned methods, there are additional procedures related to flow driving on lab-on-PCBs. These methods have been reported to a lesser extent, but they are worthy of being mentioned. The methods mentioned in this section are peristaltic PCB-based impulsion, passive microfluidics, and several lab-on-PCB compatible methods.

The microfluidic peristaltic pumps are based on microchannels' deformation to move small volumes of fluid from the inlet towards the outlet, achieving a net continuous flow $[84,85]$. In order to do so, an electronic AC signal is used for driving the fluid. These micropumps can easily change the direction of the flow. In addition, the flow rate and pressure can be modified by changing the peak-to-peak voltage values, the frequency, and the phase difference of the driving voltages. Nevertheless, they have several drawbacks, such as moving parts and large working area on the substrate.

The integration of peristaltic pumps into printed circuit boards is not easy. This task implies the development of actuators with moving parts to achieve the peristaltic effect. This could be the reason for the lack of pumps of this kind for lab-on-PCBs, if compared with other impulsion methods. However, there are several approaches of PCB-based peristaltic micropumps for lab-on-PCBs. One of these devices was reported in [86,87]. These pumps were composed of a printed circuit board and piezoelectric commercial actuators (buzzers in electronic equipment). The experimental results show a maximum working frequency of $50 \mathrm{~Hz}$ with a maximum speed of $3 \mathrm{~mm} / \mathrm{min}$ for a driven voltage of $140 \mathrm{~V}$. The same working principle was used in the device described in [88]. In this case, the maximum average flow rate was $500 \mu \mathrm{L} / \mathrm{min}$ when the peak-to-peak driven voltage was $100 \mathrm{~V}$ at $10 \mathrm{~Hz}$, the maximum backpressure being $760 \mathrm{~Pa}$. The dimensions of the PCB substrate when the pump is integrated were about $10 \times 6 \mathrm{~cm}^{2}$. This seems to be large for a integrated pump, but microfluidic circuits and sensors could be included in the remaining area, or even on the opposite side of the PCB.

As a conclusion, it is important to highlight that the main drawback is the required moving parts and its integration into the PCB substrate. That integration implies increasing both the complexity of the fabrication process and the dimensions of the device. Although the PCB substrate makes the device cheaper, the mentioned disadvantages go against the target of lab-on-PCB devices, that is, the inexpensive mass production focused on the market. In fact, up to now, the characteristics of the PCB substrate have not shown interesting advantages in the fabrication of these pumps. Unlike the systems for fluid manipulation mentioned in previous sections, in peristaltic micropumps the copper layer cannot be used for developing the actuator in charge of the liquid movement. In addition, they need external or integrated liquid reservoirs.

The surface acoustic wave (SAW) methods for manipulating fluids are commonly used in microfluidics and lab-on-chip [52,89]. The development of this kind of device using printed circuit boards is not easy due to the substrate material having to be piezoelectric. The typical application of PCBs to these devices is the connection between the radio frequency signal generator and the SAW actuator [90]. However, the microelectrodes can be developed using the copper layer of a PCB substrate. In this case, these electrodes have to be clamped to a piezoelectric substrate. This solution was reported in [91] for fluid and cell manipulations with maximum droplet velocities of about $40 \mathrm{~mm} / \mathrm{s}$.

The PCB-based liquid dispenser reported in [92] is a microfluidic pump composed of a oscillating membrane made from a flexible $\mathrm{PCB}$, and magnetically actuated via Lorentz force. Following with the same application, a PCB-based dispenser for biomedical integrates a bending CNT actuator into a PCB, which enables the induction of movement [93]. In addition, a thermally actuated one-shot liquid dispenser, with an actuation based on highly expandable microspheres on PCB has been reported [94].

On the other hand, passive microfluidics is other typical and well-known method used for driving fluids [95]. This method has also been used for printed circuit boards to develop high-performance PCB-based capillary pumps for affordable point-of-care diagnostics $[96,97]$. The flow can be created without actuation; for example, take the PCB- 
based self-breathing fuel cells $[98,99]$. The working itself leads the motion of the liquid. Despite all this, the handling of fluids is one of the most important issues for lab-on-chips and lab-on-PCBs.

There are interesting flow driving methods compatible with lab-on-PCB devices, but they have been developed using different substrates. The first one is based on the integration of thermo-expanding microspheres [100] into silicon substrates. These microspheres were also used for blocking the flow in microchannels. The second one is the impulsion system reported in $[101,102]$ which uses azobis-isobutyronitrile (AIBN) as the solid chemical propellant and a gold microheater. This device is composed of a cyclic oleofin copolymer substrate and gold as a metal. The AIBN is heated at $70{ }^{\circ} \mathrm{C}$ to produce nitrogen gas in order to impulse the liquid samples. Finally, dielectrowetting is an interesting compatible technique which creates stronger wetting forces than EWOD [103]. Droplets can be created, transported, splitted, and merged using this technique [104].

\section{Discussion and Conclusions}

The use of the copper layers of the PCB to develop actuators has provided good results. Several PCB-based actuators are easily integrable using that layer, for example, microheaters, microvalves, and electrodes. These actuators have successfully been used for driving flow on lab-on-PCBs. The level of development in the majority of them is suitable. However, the integration of these actuators has drawbacks. The first one is the increase of the area of the substrate due to the integration of the actuator. This fact means an increase of the cost of the final product, especially for single use devices. In this respect, the use of external impulsion devices for lab-on-PCBs implies smaller, simpler and cheaper PCB-chips. This is important because the PCB-chips are the most important source of benefits, especially if they are disposable. In addition, the use of external impulsion devices makes the quality control of the flow driving easy. The reason for this characteristic lies in the use of a unique device for driving fluids for many lab-on-PCBs, instead of a new integrated device for each lab-on-PCBs. Therefore, the use of external impulsion devices is a good choice for no portable lab-on-PCB devices. One drawback of these devices is the change of the tubing for each experiment due to the contamination. This trend could suggest focusing the research on the miniaturization of external devices with no integration so that the portability is applied to the whole system, that is, the electronic control device with small external impulsion devices, and more importantly, small disposable PCB chips. This implies the development of well-defined and standard fluidic and mechanical ports.

It is important to mention that the flow driven devices are not always necessary for lab-on-PCBs. Examples of these devices include the wearable detection biomedical device for real-time detection of glucose in sweat reported in [105] and a PCB-Based thermocycler for PCR [106]. These devices do not require the motion of fluids.

Table 2 summarizes the lab-on-PCB devices with the flow-driving active mechanisms mentioned in this review, except the external energy sources. The table shows the flow driving method and the actuator, the fabrication materials additional to the PCB substrate, the nature of the flow, and the application of the lab-on-PCB. In addition, Table 3 shows a quantitative comparison.

This review described the active flow driving methods for lab-on-PCB devices, mentioning their characteristics from the industrial point of view. In general, there is no perfect method because all of them have drawbacks.

The main problem with regard to marketable devices is the complex fabrication due to the integration of additional fabrication material. In addition, the method of assembly of the LoPs increases that difficulty.

Moreover, the biomedical and biochemical applications are very demanding. Among other things, they require transparency, biocompatibility, and specific ambient conditions, for example, temperature, humidity, or $\mathrm{pH}$. Particularly, these requirements have to be compatible with the flow driving method, together with the rest of the lab-on-PCB, including the sensing. All the problems have to be solved to provide consistency and relia- 
bility for both the fabrication process and the function. In this respect, the most developed method for commercial PCB-based flow driving applications, which better fulfills those requirements, is electrowetting on dielectrics. Nevertheless, it has drawbacks which could be solved with the combination of EWOD with a different flow driving method.

As can be seen in this review, lab-on-PCB devices have been developed for many biomedical and biochemical applications. However, much work has to be done towards commercial applications. This is especially challenging if taking into account the boundary conditions of the market, that is, repeatability, reliability, and acceptable fabrication processes. Even so, the research of devices of this kind is rapidly increasing, so interesting solutions are being developed day to day. The reason for this lies in the great potential of lab-on-PCB devices to provide marketable devices.

Table 2. Characteristics of active microfluidic, pressure-driven lab-on-PCBs.

\begin{tabular}{cccccc}
\hline Method & Actuator & Materials & Flow & Application & References \\
\hline Pressurized & valve & SU-8 & Samples & General Purpose & {$[40,44,46,48]$} \\
Pressurized & valve & SU-8/Au & Samples & General Purpose & {$[42,47]$} \\
Pressurized & valve & PMMA & Samples & General Purpose & {$[49]$} \\
EWOD & Electrodes & Dielectric & Droplet & General Purpose & {$[53,55,56,62]$} \\
EWOD & Electrodes & Glass/dielectric & Droplet & General Purpose & {$[54,59-61]$} \\
EWOD & Electrodes & Polymer/dielectric & Droplet & Clinical diagnosis & {$[64]$} \\
EWOD & Electrodes & SU-8/Teflon & Droplet & General Purpose & {$[58]$} \\
Osmotic & Electrodes & SU-8 & Continuous & General Purpose & {$[69,70]$} \\
Osmotic & Electrodes & $1002 F$ & Continuous & General Purpose & {$[71]$} \\
Osmotic & Electrodes & Gold & Continuous & General Purpose & {$[72]$} \\
Osmotic & Electrodes & AAO/PDMS & Continuous & General Purpose & {$[73]$} \\
Peristaltic & Piezo-disc & Brass & Continuous & General Purpose & {$[86-88]$} \\
Paraffin & Heater & Paraffin/Epoxy & Samples & General Purpose & {$[76]$} \\
Paraffin & Heater & Paraffin/PDMS & Samples & DNA extraction & {$[77]$} \\
Thermoneumatic & Heater & Paraffin/PC & Samples & DNA amplification & {$[11]$} \\
Electrolytic & Heater & Paraffin/PC & Samples & DNA amplification & {$[11]$} \\
Electrolytic & Electrodes & PMMA & Continuous & General Purpose & {$[78,79]$} \\
Electrolytic & Electrodes & Polymer/Pt & Continuous & General Purpose & {$[80]$} \\
Electrolytic & Electrodes & Polymer & Continuous & PCR and Analysis & {$[81]$} \\
Electrolytic & Electrodes & Glass & Continuous & Droplet generation & {$[82]$} \\
SAW & Electrodes & LiNbO3 & Droplet & Cell/droplet manipulation & {$[91]$} \\
Magnetic & Magnet & NdFeB & Sample & Dispenser & {$[92]$} \\
CNT-based & CNT-actuator & CNT & Sample & Dispenser & {$[93]$} \\
Microspheres & Heater & Polymer & Sample & Dispenser & {$[94]$} \\
\hline
\end{tabular}


Table 3. Lab-on-PCB devices and flow driving: a quantitative comparison.

\begin{tabular}{|c|c|c|c|c|c|}
\hline Method & $\begin{array}{c}\text { Module } \\
\text { Dimension }\end{array}$ & $\begin{array}{c}\text { Fabrication } \\
\text { Complexity/Cost }\end{array}$ & $\begin{array}{l}\text { Fluidic } \\
\text { Condition }\end{array}$ & $\begin{array}{l}\text { Channel } \\
\text { Section }\end{array}$ & Reference \\
\hline $\begin{array}{l}\text { Pressurized } \\
\text { chamber }\end{array}$ & $3 \times 2 \mathrm{~cm}^{2}$ & Medium/Low & $\begin{array}{c}\text { Average speed } \\
41 \mathrm{~mm} / \mathrm{s}\end{array}$ & $0.3 \times 1 \mathrm{~mm}^{2}$ & [40] \\
\hline $\begin{array}{l}\text { Pressurized } \\
\text { chamber }\end{array}$ & $7.5 \times 4.5 \mathrm{~cm}^{2}$ & Medium/Low & $\begin{array}{c}\text { Average speed } \\
16.25 \mathrm{~mm} / \mathrm{s}\end{array}$ & $0.3 \times 0.5 \mathrm{~mm}^{2}$ & [48] \\
\hline $\begin{array}{l}\text { Pressurized } \\
\text { chamber }\end{array}$ & $6 \times 1 \mathrm{~cm}^{2}$ & High/High & $\begin{array}{l}\text { Average speed } \\
271 \mathrm{~mm} / \mathrm{s}\end{array}$ & $0.35 \times 0.5 \mathrm{~mm}^{2}$ & [47] \\
\hline $\begin{array}{c}\text { Pressurized } \\
\text { chamber }\end{array}$ & $6 \times 5 \mathrm{~cm}^{2}$ & Low / Low & $\begin{array}{c}\text { Average flow rate } \\
1.4 \mu \mathrm{L} / \mathrm{s}\end{array}$ & $1 \times 1.1 \mathrm{~mm}^{2}$ & [49] \\
\hline EWOD & $\begin{array}{c}8.9 \times 8.9 \mathrm{~cm}^{2} \\
1024 \text { electrodes }\end{array}$ & Low /Low & $\begin{array}{l}\text { Max speed } \\
100 \mathrm{~mm} / \mathrm{s}\end{array}$ & No channel & [53] \\
\hline EWOD & $\begin{array}{c}\sim 14 \times 10 \mathrm{~cm}^{2} \\
6 \text { electrodes }\end{array}$ & Low /Low & $\begin{array}{l}\text { Max speed } \\
3 \mathrm{~mm} / \mathrm{s}\end{array}$ & No channel & [56] \\
\hline EWOD & $\begin{array}{c}\mathrm{N} / \mathrm{A} \\
64 \text { electrodes }\end{array}$ & Low / Low & $\begin{array}{l}\text { Velocity } \\
6-13 \mathrm{~mm} / \mathrm{s}\end{array}$ & No channel & {$[61]$} \\
\hline EWOD & $\begin{array}{l}12.78 \times 8.55 \mathrm{~cm}^{2} \\
\mathrm{~N} / \text { A electrodes }\end{array}$ & Medium/Low & $\mathrm{N} / \mathrm{A}$ & No channel & {$[63,64]$} \\
\hline EWOD & $\begin{array}{c}5 \times 5 \mathrm{~cm}^{2} \\
576 \text { electrodes }\end{array}$ & High/Low & $\mathrm{N} / \mathrm{A}$ & No channel & [58] \\
\hline Osmotic & $\begin{array}{l}\sim 4.5 \times 4.5 \mathrm{~cm}^{2} \\
6 \text { pumps }\end{array}$ & Medium/Low & $\begin{array}{l}\text { Flow rate } \\
1 \mu \mathrm{L} / \mathrm{min}\end{array}$ & $0.2 \times 0.1 \mathrm{~mm}^{2}$ & {$[69,70]$} \\
\hline Osmotic & $\begin{array}{c}7.62 \times 2.54 \mathrm{~cm}^{2} \\
1 \text { pump }\end{array}$ & High/Low & $\begin{array}{l}\text { Max speed } \\
800 \mu \mathrm{m} / \mathrm{s}\end{array}$ & $0.3 \times 0.07 \mathrm{~mm}^{2}$ & {$[71]$} \\
\hline Osmotic & $\begin{array}{l}2 \times 1 \mathrm{~cm}^{2} \\
1 \text { pump }\end{array}$ & Low / High & $\begin{array}{l}\text { Max speed } \\
750 \mu \mathrm{m} / \mathrm{s}\end{array}$ & $\mathrm{N} / \mathrm{A}$ & [72] \\
\hline Osmotic & $\begin{array}{c}15 \times 15 \mathrm{~cm}^{2} \\
1 \text { pump }\end{array}$ & High/Medium & $\begin{array}{l}\text { Flow rate } \\
8 \mu \mathrm{L} / \mathrm{min}\end{array}$ & $\begin{array}{l}\text { Nanopore } \\
\text { Membrane }\end{array}$ & [73] \\
\hline Peristaltic & $\begin{array}{l}\sim 10 \times 6 \mathrm{~cm}^{2} \\
1 \text { pump }\end{array}$ & Low / Low & $\begin{array}{l}\text { Average flow rate } \\
500 \mu \mathrm{L} / \mathrm{min}\end{array}$ & $\mathrm{N} / \mathrm{A}$ & [88] \\
\hline Peristaltic & $\begin{array}{c}\sim 0.4 \times 0.25 \mathrm{~cm}^{2} \\
1 \text { pump }\end{array}$ & Low / Low & $\begin{array}{l}\text { Max flow rate } \\
1500 \mu \mathrm{L} / \mathrm{min}\end{array}$ & $\mathrm{N} / \mathrm{A}$ & {$[86,87]$} \\
\hline Paraffin & $5.5 \times 4 \mathrm{~cm}^{2}$ & High/Low & $\begin{array}{l}\text { Max flow rate } \\
240 \mu \mathrm{L} / \mathrm{min}\end{array}$ & $\mathrm{N} / \mathrm{A}$ & [76] \\
\hline Thermoneumatic & $10 \times 6 \mathrm{~cm}^{2}$ & High/Low & $\begin{array}{l}\text { Moved volumen } \\
\qquad 60 \mu \mathrm{L}\end{array}$ & $\begin{array}{c}\text { Min } \\
0.3 \times 1 \mathrm{~mm}^{2}\end{array}$ & [11] \\
\hline Electrolytic & $10 \times 6 \mathrm{~cm}^{2}$ & High /Low & $\begin{array}{c}\text { Max flow rate } \\
0.8 \mu \mathrm{L} / \mathrm{min}\end{array}$ & $\begin{array}{c}\text { Min } \\
0.3 \times 1 \mathrm{~mm}^{2}\end{array}$ & {$[11]$} \\
\hline Electrolytic & $10 \times 6.5 \mathrm{~cm}^{2}$ & Medium/High & $\begin{array}{l}\text { Flow rate-backpressure } \\
31.6 \mathrm{~mL} / \mathrm{min}-547 \mathrm{kPa}\end{array}$ & $1.5 \times 2.5 \mathrm{~mm}$ & {$[78,79]$} \\
\hline Electrolytic & $2.5 \times 1 \mathrm{~cm}^{2}$ & Low/Low & $\begin{array}{l}\text { Max flow rate } \\
135 \mu \mathrm{L} / \mathrm{min}\end{array}$ & $1 \times 0.025 \mathrm{~mm}$ & [80] \\
\hline Electrolytic & $8 \times 6 \mathrm{~cm}^{2}$ & High/Low & $\begin{array}{c}\text { Max flow rate } \\
0.1-1 \mu \mathrm{L} / \mathrm{s}\end{array}$ & $\mathrm{N} / \mathrm{A}$ & [81] \\
\hline Electrolytic & $\mathrm{N} / \mathrm{A}$ & Medium/Low & $\begin{array}{l}\text { Max flow rate } \\
100 \mu \mathrm{L} / \mathrm{min}\end{array}$ & $0.15 \times 0.06 \mathrm{~mm}$ & [82] \\
\hline SAW & $11 \times 11 \mathrm{~cm}$ & Low/Medium & $\begin{array}{l}\text { Max speed } \\
40 \mathrm{~mm} / \mathrm{s}\end{array}$ & $0.15 \times 0.06 \mathrm{~mm}$ & [91] \\
\hline Magnetic & $\sim 4 \times 3 \mathrm{~cm}$ & Low/Low & $\mathrm{N} / \mathrm{A}$ & $1 \times 1 \mathrm{~mm}$ & [93] \\
\hline
\end{tabular}

Funding: This research received no external funding.

Institutional Review Board Statement: Not applicable.

Informed Consent Statement: Not applicable.

Data Availability Statement: Data is contained within the article. 
Acknowledgments: I would like to thank Mars Tu for his invaluable support. In addition, I want to thank the Microsystems Group of the University of Seville for giving me the opportunity to be a part of the group.

Conflicts of Interest: The authors declare no conflict of interest.

\author{
Abbreviations \\ The following abbreviations are used in this manuscript: \\ MDPI Multidisciplinary Digital Publishing Institute \\ DOAJ Directory of open access journals \\ TLA Three letter acronym \\ LD linear dichroism
}

\title{
References
}

1. Moschou, D.; Tserepi, A. The lab-on-PCB approach: Tackling the $\mu$ TAS commercial upscaling bottleneck. Lab Chip 2017, 17, 1388-1405. [CrossRef] [PubMed]

2. Zhao, W.; Tian, S.; Huang, L.; Liu, K.; Dong, L. The review of Lab-on-PCB for biomedical application. Electrophoresis 2020, 41, 1433-1445. [CrossRef] [PubMed]

3. Abgrall, P.; Gue, A. Lab-on-chip technologies: Making a microfluidic network and coupling it into a complete microsystem-A review. J. Micromechan. Microeng. 2007, 17, R15. [CrossRef]

4. Dittrich, P.S.; Manz, A. Lab-on-a-chip: Microfluidics in drug discovery. Nat. Rev. Drug Disc. 2006, 5, 210-218. [CrossRef]

5. Haeberle, S.; Zengerle, R. Microfluidic platforms for lab-on-a-chip applications. Lab Chip 2007, 7, 1094-1110. [CrossRef]

6. Merkel, T.; Graeber, M.; Pagel, L. A new technology for fluidic microsystems based on PCB technology. Sens. Act. A Phys. 1999, 77, 98-105. [CrossRef]

7. Nguyen, N.T.; Hejazian, M.; Ooi, C.H.; Kashaninejad, N. Recent advances and future perspectives on microfluidic liquid handling. Micromachines 2017, 8, 186. [CrossRef]

8. Terry, S.C.; Jerman, J.H.; Angell, J.B. A gas chromatographic air analyzer fabricated on a silicon wafer. IEEE Trans. Electr. Dev. 1979, 26, 1880-1886. [CrossRef]

9. Harrison, D.J.; Glavina, P.; Manz, A. Towards miniaturized electrophoresis and chemical analysis systems on silicon: An alternative to chemical sensors. Sens. Act. B Chem. 1993, 10, 107-116. [CrossRef]

10. Boyd-Moss, M.; Baratchi, S.; Di Venere, M.; Khoshmanesh, K. Self-contained microfluidic systems: A review. Lab Chip 2016, 16, 3177-3192. [CrossRef]

11. Liu, R.H.; Yang, J.; Lenigk, R.; Bonanno, J.; Grodzinski, P. Self-contained, fully integrated biochip for sample preparation, polymerase chain reaction amplification, and DNA microarray detection. Anal. Chem. 2004, 76, 1824-1831. [CrossRef] [PubMed]

12. Salado, G.F. Self-Contained Microfluidic Platform for General Purpose Lab-on-Chip Using pcb-mems Technology. Ph.D. Thesis, Universidad de Sevilla, Sevilla, Spain, 2017.

13. Chang, Y.J.; Hui, Y. Progress of Microfluidics Based on Printed Circuit Board and its Applications. Chin. J. Anal. Chem. 2019, 47, 965-975. [CrossRef]

14. Vasilakis, N.; Papadimitriou, K.; Evans, D.; Morgan, H.; Prodromakis, T. The lab-on-PCB framework for affordable, electronicbased point-of-care diagnostics: From design to manufacturing. In Proceedings of the 2016 IEEE Healthcare Innovation Point-Of-Care Technologies Conference (HI-POCT), IEEE, Cancun, Mexico, 9-11 November 2016; pp. 126-129.

15. ultimatepcb. 2021. Available online: https://www.ultimatepcb.com/services/pcb-fabrication (accessed on 29 January 2021).

16. Jobst, G.; Moser, I.; Svasek, P.; Varahram, M.; Trajanoski, Z.; Wach, P.; Kotanko, P.; Skrabal, F.; Urban, G. Mass producible miniaturized flow through a device with a biosensor array. Sens. Act. B Chem. 1997, 43, 121-125. [CrossRef]

17. Wego, A.; Pagel, L. A self-filling micropump based on PCB technology. Sens. Act. A Phys. 2001, 88, 220-226. [CrossRef]

18. Wego, A.; Glock, H.W.; Pagel, L.; Richter, S. Investigations on thermo-pneumatic volume actuators based on PCB technology. Sens. Act. A Phys. 2001, 93, 95-102. [CrossRef]

19. Wego, A.; Richter, S.; Pagel, L. Fluidic microsystems based on printed circuit board technology. J. Micromech. Microeng. 2001, 11, 528. [CrossRef]

20. Gaßmann, S.; Ibendorf, I.; Pagel, L. Realization of a flow injection analysis in PCB technology. Sens. Act. A Phys. 2007, 133, 231-235. [CrossRef]

21. Tsao, C.W.; DeVoe, D.L. Bonding of thermoplastic polymer microfluidics. Microfluid. Nanofluidics 2009, 6, 1-16. [CrossRef]

22. Thorsen, T.; Maerkl, S.J.; Quake, S.R. Microfluidic large-scale integration. Science 2002, 298, 580-584. [CrossRef]

23. Wang, Y.; Lin, W.Y.; Liu, K.; Lin, R.J.; Selke, M.; Kolb, H.C.; Zhang, N.; Zhao, X.Z.; Phelps, M.E.; Shen, C.K.; et al. An integrated microfluidic device for large-scale in situ click chemistry screening. Lab Chip 2009, 9, 2281-2285. [CrossRef]

24. Liu, J.; Jasim, I.; Shen, Z.; Zhao, L.; Dweik, M.; Zhang, S.; Almasri, M. A microfluidic based biosensor for rapid detection of Salmonella in food products. PLOS ONE 2019, 14, e0216873. [CrossRef] 
25. Wilhelm, E.; Neumann, C.; Duttenhofer, T.; Pires, L.; Rapp, B.E. Connecting microfluidic chips using a chemically inert, reversible, multichannel chip-to-world-interface. Lab Chip 2013, 13, 4343-4351. [CrossRef]

26. Scott, A.; Au, A.K.; Vinckenbosch, E.; Folch, A. A microfluidic D-subminiature connector. Lab Chip 2013, 13, 2036-2039. [CrossRef] [PubMed]

27. Temiz, Y.; Lovchik, R.D.; Kaigala, G.V.; Delamarche, E. Lab-on-a-chip devices: How to close and plug the lab? Microelectron. Eng. 2015, 132, 156-175. [CrossRef]

28. Wagler, P.F.; Tangen, U.; Maeke, T.; Chemnitz, S.; Juenger, M.; McCaskill, J.S. Molecular systems on-chip (MSoC) steps forward for programmable biosystems. In Smart Structures and Materials 2004: Smart Electronics, MEMS, BioMEMS, and Nanotechnology; International Society for Optics and Photonics: San Diego, CA, USA 2004; Volume 5389, pp. 298-305.

29. Pittet, P.; Lu, G.N.; Galvan, J.M.; Ferrigno, R.; Blum, L.J.; Leca-Bouvier, B.D. PCB technology-based electrochemiluminescence microfluidic device for low-cost portable analytical systems. IEEE Sens. J. 2008, 8, 565-571. [CrossRef]

30. Kontakis, K.; Petropoulos, A.; Kaltsas, G.; Speliotis, T.; Gogolides, E. A novel microfluidic integration technology for PCB-based devices: Application to microflow sensing. Microelectron. Eng. 2009, 86, 1382-1384. [CrossRef]

31. Moschou, D.; Trantidou, T.; Regoutz, A.; Carta, D.; Morgan, H.; Prodromakis, T. Surface and electrical characterization of $\mathrm{Ag} / \mathrm{AgCl}$ pseudo-reference electrodes manufactured with commercially available PCB technologies. Sensors 2015, 15, 1810218113. [CrossRef]

32. Fu, Y.; Yuan, Q.; Guo, J. Lab-on-PCB-based micro-cytometer for circulating tumor cells detection and enumeration. Microfluid. Nanofluidics 2017, 21, 20. [CrossRef]

33. Sánchez, J.A.; Henry, O.; Joda, H.; Solnestam, B.W.; Kvastad, L.; Johansson, E.; Akan, P.; Lundeberg, J.; Lladach, N.; Ramakrishnan, D.; et al. Multiplex PCB-based electrochemical detection of cancer biomarkers using MLPA-barcode approach. Biosens. Bioelectron. 2016, 82, 224-232.

34. Cabello, M.; Aracil, C.; Perdigones, F.; Quero, J.M. Conditioning lab on PCB to control temperature and mix fluids at the microscale for biomedical applications. In Proceedings of the 2017 Spanish Conference on Electron Devices (CDE), IEEE, Barcelona, Spain, 8-10 February 2017; pp. 1-4.

35. Kaprou, G.D.; Papadopoulos, V.; Papageorgiou, D.P.; Kefala, I.; Papadakis, G.; Gizeli, E.; Chatzandroulis, S.; Kokkoris, G.; Tserepi, A. Ultrafast, low-power, PCB manufacturable, continuous-flow microdevice for DNA amplification. Anal. Bioanal. Chem. 2019, 411, 5297-5307. [CrossRef] [PubMed]

36. Cabello, M.; Mozo, M.; De la Cerda, B.; Aracil, C.; Diaz-Corrales, F.J.; Perdigones, F.; Valdes-Sanchez, L.; Relimpio, I.; Bhattacharya, S.S.; Quero, J.M. Electrostimulation in an autonomous culture lab-on-chip provides neuroprotection of a retinal explant from a retinitis pigmentosa mouse-model. Sens. Act. B Chem. 2019, 288, 337-346. [CrossRef]

37. Jolly, P.; Rainbow, J.; Regoutz, A.; Estrela, P.; Moschou, D. A PNA-based Lab-on-PCB diagnostic platform for rapid and high sensitivity DNA quantification. Biosens. Bioelectron. 2019, 123, 244-250. [CrossRef] [PubMed]

38. Dutta, G.; Regoutz, A.; Moschou, D. Enzyme-assisted glucose quantification for a painless Lab-on-PCB patch implementation. Biosens. Bioelectron. 2020, 167, 112484. [CrossRef] [PubMed]

39. El Fissi, L.; Fernández, R.; García, P.; Calero, M.; García, J.V.; Jiménez, Y.; Arnau, A.; Francis, L.A. OSTEMER polymer as a rapid packaging of electronics and microfluidic system on PCB. Sens. Act. A Phys. 2019, 285, 511-518. [CrossRef]

40. Flores, G.; Perdigones, F.; Aracil, C.; Quero, J. Pressurization method for controllable impulsion of liquids in microfluidic platforms. Microelectron. Eng. 2015, 140, 11-17. [CrossRef]

41. Moreno, J.; Perdigones, F.; Quero, J. Fabrication process of a SU-8 monolithic pressurized microchamber for pressure driven microfluidic applications. In Proceedings of the 8th Spanish Conference on Electron Devices, CDE'2011, IEEE, Palma de Mallorca, Spain, 8-11 October 2011; pp. 1-4.

42. Moreno, J.M.; Quero, J.M. A novel single-use SU-8 microvalve for pressure-driven microfluidic applications. J. Micromech. Microeng. 2009, 20, 015005. [CrossRef]

43. Aracil, C.; Quero, J.M.; Luque, A.; Moreno, J.M.; Perdigones, F. Pneumatic impulsion device for microfluidic systems. Sens. Act. A Phys. 2010, 163, 247-254. [CrossRef]

44. Perdigones, F.; Aracil, C.; Moreno, J.M.; Luque, A.; Quero, J.M. Highly integrable pressurized microvalve for portable SU-8 microfluidic platforms. J. Microelectromech. Syst. 2013, 23, 398-405. [CrossRef]

45. Aracil, C.; Perdigones, F.; Moreno, J.M.; Quero, J.M. BETTS: bonding, exposing and transferring technique in SU-8 for microsystems fabrication. J. Micromech. Microeng. 2010, 20, 035008. [CrossRef]

46. Flores, G.; Aracil, C.; Perdigones, F.; Quero, J. Low consumption single-use microvalve for microfluidic PCB-based platforms. J. Micromech. Microeng. 2014, 24, 065013. [CrossRef]

47. Aracil, C.; Perdigones, F.; Moreno, J.M.; Luque, A.; Quero, J.M. Portable Lab-on-PCB platform for autonomous micromixing. Microelectron. Eng. 2015, 131, 13-18. [CrossRef]

48. Flores, G.; Aracil, C.; Perdigones, F.; Quero, J.M. Lab-protocol-on-PCB: Prototype of a laboratory protocol on printed circuit board using MEMS technologies. Microelectron. Eng. 2018, 200, 26-31. [CrossRef]

49. Perdigones, F.; Franco, E.; Salvador, B.; Flores, G.; Quero, J.M. Highly integrable microfluidic impulsion system for precise displacement of liquids on lab on PCBs. J. Microelectromech. Syst. 2018, 27, 479-486. [CrossRef]

50. Cho, S.K.; Moon, H.; Kim, C.J. Creating, transporting, cutting, and merging liquid droplets by electrowetting-based actuation for digital microfluidic circuits. J. Microelectromech. Syst. 2003, 12, 70-80. 
51. Choi, K.; Ng, A.H.; Fobel, R.; Wheeler, A.R. Digital microfluidics. Ann. Rev. Anal. Chem. 2012, 5, 413-440. [CrossRef]

52. Luo, J.; Fu, Y.Q.; Li, Y.; Du, X.; Flewitt, A.; Walton, A.; Milne, W. Moving-part-free microfluidic systems for lab-on-a-chip. J. Micromech. Microeng. 2009, 19, 054001. [CrossRef]

53. Umapathi, U.; Chin, S.; Shin, P.; Koutentakis, D.; Ishii, H. Scaling Electrowetting with Printed Circuit Boards for Large Area Droplet Manipulation. MRS Adv. 2018, 3, 1475-1483. [CrossRef]

54. Abdelgawad, M.; Wheeler, A.R. Rapid prototyping in copper substrates for digital microfluidics. Adv. Mater. 2007, 19, 133-137. [CrossRef]

55. Li, Y.; Chen, R.; Baker, R.J. A fast fabricating electro-wetting platform to implement large droplet manipulation. In Proceedings of the 2014 IEEE 57th International Midwest Symposium on Circuits and Systems (MWSCAS), IEEE, College Station, TX, USA, 3-6 August 2014; pp. 326-329.

56. Meimandi, A.; Seyedsadrkhani, N.; Jahanshahi, A. Development of an Electrowetting Digital Microfluidics Platform using Low-cost Materials. In Proceedings of the 2019 27th Iranian Conference on Electrical Engineering (ICEE), IEEE, Yazd, Iran, 30 April-2 May 2019; pp. 154-157.

57. Yi, Z.; Feng, H.; Zhou, X.; Shui, L. Design of an open electrowetting on dielectric device based on printed circuit board by using a parafilm m. Front. Phys. 2020, 8, 193. [CrossRef]

58. Nardecchia, M.; Lovecchio, N.; Llorca, P.R.; Caputo, D.; de Cesare, G.; Nascetti, A. 2-D digital microfluidic system for droplet handling using Printed Circuit Board technology. In Proceedings of the 2015 XVIII AISEM Annual Conference, IEEE, Trento, Italy, 3-5 February 2015; pp. 1-4.

59. Gong, M.; Kim, C.J. Two-dimensional digital microfluidic system by multilayer printed circuit board. In Proceedings of the 18th IEEE International Conference on Micro Electro Mechanical Systems, MEMS 2005, IEEE, Miami Beach, FL, USA, 30 January-3 February 2005; pp. 726-729.

60. Gong, J. All-electronic droplet generation on-chip with real-time feedback control for EWOD digital microfluidics. Lab Chip 2008, 8, 898-906. [CrossRef]

61. Gong, J.; Kim, C.J. Direct-referencing two-dimensional-array digital microfluidics using multilayer printed circuit board. J. Microelectromech. Syst. 2008, 17, 257-264. [CrossRef] [PubMed]

62. Braun, T.; Becker, K.F.; Koch, M.; Jung, E.; Lienemann, J.; Korvink, J.; Kahle, R.; Bauer, J.; Aschenbrenner, R.; Reichl, H. Contactless component handling on PCB using EWOD principles. In Proceedings of the 2008 10th Electronics Packaging Technology Conference, IEEE, Singapore, 9-12 December 2008; pp. 186-192.

63. Boles, D.J.; Benton, J.L.; Siew, G.J.; Levy, M.H.; Thwar, P.K.; Sandahl, M.A.; Rouse, J.L.; Perkins, L.C.; Sudarsan, A.P.; Jalili, R.; et al. Droplet-based pyrosequencing using digital microfluidics. Anal. Chem. 2011, 83, 8439-8447. [CrossRef] [PubMed]

64. Sista, R.; Hua, Z.; Thwar, P.; Sudarsan, A.; Srinivasan, V.; Eckhardt, A.; Pollack, M.; Pamula, V. Development of a digital microfluidic platform for point of care testing. Lab Chip 2008, 8, 2091-2104. [CrossRef]

65. Pollack, M.G.; Pamula, V.K.; Srinivasan, V.; Eckhardt, A.E. Applications of electrowetting-based digital microfluidics in clinical diagnostics. Expert Rev. Mol. Diag. 2011, 11, 393-407. [CrossRef] [PubMed]

66. Li, J. Current commercialization status of electrowetting-on-dielectric (EWOD) digital microfluidics. Lab Chip 2020, 20, 1705-1712. [CrossRef]

67. Wang, X.; Cheng, C.; Wang, S.; Liu, S. Electroosmotic pumps and their applications in microfluidic systems. Microfluid. Nanofluidics 2009, 6, 145-162. [CrossRef]

68. Li, L.; Wang, X.; Pu, Q.; Liu, S. Advancement of electroosmotic pump in microflow analysis: A review. Anal. Chim. Acta 2019, 1060, 1-16. [CrossRef]

69. Gassmann, S.; Pagel, L.; Luque, A.; Perdigones, F.; Aracil, C. Fabrication of electroosmotic micropump using PCB and SU-8. In Proceedings of the IECON 2012 38th Annual Conference on IEEE Industrial Electronics Society, IEEE, Montreal, QC, Canada, 25-28 October 2012; pp. 3958-3961.

70. Luque, A.; Soto, J.M.; Perdigones, F.; Aracil, C.; Quero, J.M. Electroosmotic impulsion device for integration in PCB-MEMS. In Proceedings of the 2013 Spanish Conference on Electron Devices, IEEE, Valladolid, Spain, 12-14 February 2013 ; pp. 119-122.

71. Wu, L.L.; Babikian, S.; Li, G.P.; Bachman, M. Microfluidic printed circuit boards. In Proceedings of the 2011 IEEE 61 st electronic components and technology conference (ECTC), IEEE, Lake Buena Vista, FL, USA, 31 May-3 June 2011; pp. $1576-1581$.

72. Mirzajani, H.; Cheng, C.; Wu, J.; Ivanoff, C.S.; Aghdam, E.N.; Ghavifekr, H.B. Design and characterization of a passive, disposable wireless AC-electro lab-on-a-film for particle and fluid manipulation. Sens. Act. B Chem. 2016, 235, 330-342. [CrossRef]

73. Babikian, S.; Jinsenji, M.; Bachman, M.; Li, G. Surface Mount Electroosmotic Pump for Integrated Microfluidic Printed Circuit Boards. In Proceedings of the 2018 IEEE 68th Electronic Components and Technology Conference (ECTC), IEEE, San Diego, CA, USA, 29 May-1 June 2018; pp. 498-503.

74. Ogden, S.; Klintberg, L.; Thornell, G.; Hjort, K.; Bodén, R. Review on miniaturized paraffin phase change actuators, valves, and pumps. Microfluid. Nanofluidics 2014, 17, 53-71. [CrossRef]

75. Walsh, D.; Zoller, P. Standard Pressure Volume Temperature Data for Polymers; CRC Press: Boca Raton, FL, USA, 1995.

76. Bodén, R.; Lehto, M.; Margell, J.; Hjort, K.; Schweitz, J.Å. On-chip liquid storage and dispensing for lab-on-a-chip applications. J. Micromech. Microeng. 2008, 18, 075036.

77. Wang, Y.; Li, Z.; Huang, X.; Ji, W.; Ning, X.; Liu, K.; Tan, J.; Yang, J.; Ho, H.p.; Wang, G. On-board control of wax valve on active centrifugal microfluidic chip and its application for plasmid DNA extraction. Microfluid. Nanofluidics 2019, 23, 112. [CrossRef] 
78. Kim, H.; Hwang, H.; Baek, S.; Kim, D. Design, fabrication and performance evaluation of a printed-circuit-board microfluidic electrolytic pump for lab-on-a-chip devices. Sens. Act. A Phys. 2018, 277, 73-84. [CrossRef]

79. Kim, H.; Hwang, H.; Kim, J.; Kim, D. An Electrolytic Micropump Fabricated on Printed Circuit Board for Integrated Microfluidic System. In Proceedings of the 21st International Conference on Miniaturized Systems for Chemistry and Life Sciences, Savannah, GA, USA, 22-26 October 2017; pp. 641-642.

80. Pagonis, D.; Petropoulos, A.; Kaltsas, G. A pumping actuator implemented on a PCB substrate by employing water electrolysis. Microelectron. Eng. 2012, 95, 65-70. [CrossRef]

81. Schumacher, S.; Nestler, J.; Otto, T.; Wegener, M.; Ehrentreich-Förster, E.; Michel, D.; Wunderlich, K.; Palzer, S.; Sohn, K.; Weber, A.; et al. Highly-integrated lab-on-chip system for point-of-care multiparameter analysis. Lab Chip 2012, 12, 464-473. [CrossRef] [PubMed]

82. Li, J.; Wang, Y.; Dong, E.; Chen, H. USB-driven microfluidic chips on printed circuit boards. Lab Chip 2014, 14, 860-864. [CrossRef]

83. Liu, R.H.; Bonanno, J.; Yang, J.; Lenigk, R.; Grodzinski, P. Single-use, thermally actuated paraffin valves for microfluidic applications. Sens. Act. B Chem. 2004, 98, 328-336. [CrossRef]

84. Wang, Y.N.; Fu, L.M. Micropumps and biomedical applications-A review. Microelectron. Eng. 2018, 195, 121-138. [CrossRef]

85. Laser, D.J.; Santiago, J.G. A review of micropumps. J. Micromech. Microeng. 2004, 14, R35. [CrossRef]

86. Huang, X.; Nguyen, N.T. Development of a peristaltic pump in printed circuit boards. J. Micromechatron. 2005, 3, 1-13.

87. Nguyen, N.T.; Huang, X. Miniature valveless pumps based on printed circuit board technique. Sens. Act. A Phys. 2001, 88, 104-111. [CrossRef]

88. Wang, D.H.; Tang, L.K.; Peng, Y.H.; Yu, H.Q. Principle and structure of a printed circuit board process-based piezoelectric microfluidic pump integrated into printed circuit board. J. Intel. Mater. Syst. Struc. 2019, 30, 2595-2604. [CrossRef]

89. Schmid, L.; Wixforth, A.; Weitz, D.A.; Franke, T. Novel surface acoustic wave (SAW)-driven closed PDMS flow chamber. Microfluid. Nanofluidics 2012, 12, 229-235. [CrossRef]

90. Weser, R.; Darinskii, A.; Weihnacht, M.; Schmidt, H. Experimental and numerical investigations of mechanical displacements in surface acoustic wave bounded beams. Ultrasonics 2020, 106, 106077. [CrossRef] [PubMed]

91. Mikhaylov, R.; Wu, F.; Wang, H.; Clayton, A.; Sun, C.; Xie, Z.; Liang, D.; Dong, Y.; Yuan, F.; Moschou, D.; et al. Development and characterisation of acoustofluidic devices using detachable electrodes made from PCB. Lab Chip 2020, 20, 1807-1814. [CrossRef] [PubMed]

92. Hintermüller, M.A.; Jakoby, B. A Diffusor/Nozzle Pump Based on a Magnetically Actuated Flexible PCB Diaphragm. Proceedings 2018, 2, 1077.

93. Addinall, R.; Sugino, T.; Neuhaus, R.; Kosidlo, U.; Tonner, F.; Glanz, C.; Kolaric, I.; Bauernhansl, T.; Asaka, K. Integration of CNT-based actuators for bio-medical applications-Example printed circuit board CNT actuator pipette. In Proceedings of the 2014 IEEE/ASME International Conference on Advanced Intelligent Mechatronics, IEEE, Besacon, France, 8-11 July 2014 ; pp. 1436-1441.

94. Roxhed, N.; Rydholm, S.; Samel, B.; van der Wijngaart, W.; Griss, P.; Stemme, G. Low cost device for precise microliter range liquid dispensing. In Proceedings of the 17th IEEE International Conference on Micro Electro Mechanical Systems. Maastricht MEMS 2004 Technical Digest, IEEE, Maastricht, The Netherlands, 25-29 January 2004; pp. 326-329.

95. Narayanamurthy, V.; Jeroish, Z.; Bhuvaneshwari, K.; Bayat, P.; Premkumar, R.; Samsuri, F.; Yusoff, M.M. Advances in passively driven microfluidics and lab-on-chip devices: A comprehensive literature review and patent analysis. RSC Adv. 2020, 10, 11652-11680. [CrossRef]

96. Vasilakis, N.; Papadimitriou, K.I.; Morgan, H.; Prodromakis, T. High-performance PCB-based capillary pumps for affordable point-of-care diagnostics. Microfluid. Nanofluidics 2017, 21, 103. [CrossRef] [PubMed]

97. Vasilakis, N.; Moschou, D.; Carta, D.; Morgan, H.; Prodromakis, T. Long-lasting FR-4 surface hydrophilisation towards commercial PCB passive microfluidics. Appl. Surf. Sci. 2016, 368, 69-75. [CrossRef]

98. Schmitz, A.; Tranitz, M.; Wagner, S.; Hahn, R.; Hebling, C. Planar self-breathing fuel cells. J. Power Sources 2003, $118,162-171$. [CrossRef]

99. Schmitz, A.; Wagner, S.; Hahn, R.; Uzun, H.; Hebling, C. Stability of planar PEMFC in printed circuit board technology. J. Power Sources 2004, 127, 197-205. [CrossRef]

100. Griss, P.; Andersson, H.; Stemme, G. Expandable microspheres for the handling of liquids. Lab Chip 2002, 2, 117-120. [CrossRef] [PubMed]

101. Hong, C.C.; Murugesan, S.; Kim, S.; Beaucage, G.; Choi, J.W.; Ahn, C.H. A functional on-chip pressure generator using solid chemical propellant for disposable lab-on-a-chip. Lab Chip 2003, 3, 281-286. [CrossRef] [PubMed]

102. Ahn, C.H. Disposable polymer "smart" lab-on-a-chip for point-of-care testing (POCT) in clinical diagnostics. In Proceedings of the 13th International Conference on Solid-State Sensors, Actuators and Microsystems, 2005, TRANSDUCERS'05, IEEE, Digest of Technical Papers, Seoul, Korea, 5-9 June 2005; Volume 1, pp. 437-440.

103. Edwards, A.M.; Brown, C.V.; Newton, M.I.; McHale, G. Dielectrowetting: The past, present and future. Cur. Opin. Col. Interface Sci. 2018, 36, 28-36. [CrossRef]

104. Geng, H.; Feng, J.; Stabryla, L.M.; Cho, S.K. Dielectrowetting manipulation for digital microfluidics: Creating, transporting, splitting, and merging of droplets. Lab Chip 2017, 17, 1060-1068. [CrossRef] 
105. Martín, A.; Kim, J.; Kurniawan, J.F.; Sempionatto, J.R.; Moreto, J.R.; Tang, G.; Campbell, A.S.; Shin, A.; Lee, M.Y.; Liu, X.; et al. Epidermal microfluidic electrochemical detection system: Enhanced sweat sampling and metabolite detection. ACS Sen. 2017, 2, 1860-1868. [CrossRef] [PubMed]

106. Kaprou, G.D.; Papadopoulos, V.; Loukas, C.M.; Kokkoris, G.; Tserepi, A. Towards PCB-Based Miniaturized Thermocyclers for DNA Amplification. Micromachines 2020, 11, 258. [CrossRef] 